\title{
Advancing a new index for measuring household vulnerability to food insecurity
}

Article

Accepted Version

Creative Commons: Attribution-Noncommercial-No Derivative Works 4.0

Ibok, O., Osbahr, H. and Srinivasan, C. (2019) Advancing a new index for measuring household vulnerability to food insecurity. Food Policy, 84. pp. 10-20. ISSN 0306-9192 doi: https://doi.org/10.1016/j.foodpol.2019.01.011 Available at https://centaur.reading.ac.uk/81962/

It is advisable to refer to the publisher's version if you intend to cite from the work. See Guidance on citing.

To link to this article DOI: http://dx.doi.org/10.1016/j.foodpol.2019.01.011

Publisher: Elsevier

All outputs in CentAUR are protected by Intellectual Property Rights law, including copyright law. Copyright and IPR is retained by the creators or other copyright holders. Terms and conditions for use of this material are defined in the End User Agreement.

\section{www.reading.ac.uk/centaur}

\section{CentAUR}

Central Archive at the University of Reading

Reading's research outputs online 


\title{
Advancing a new index for measuring household vulnerability to food insecurity
}

Otu W. Ibok*, Henny Osbahr, Chittur Srinivasan

School of Agriculture, Policy, and Development; University of Reading, UK

*Corresponding Author: otuibok@yahoo.com; o.w.ibok@pgr.reading.ac.uk

\begin{abstract}
This paper develops a Vulnerability to Food Insecurity Index (VFII). Currently, there is no standard indicator of vulnerability analysis in food security research, and this paper responds to this challenge. The primary objective in this paper is to demonstrate how to develop a potential indicator and establish its validity through comparison with other traditional food security indicators, such as per capita calorie consumption (PCC), food consumption score (FCS) and the coping strategy index (CPI). Structurally, Vulnerability to Food Insecurity Index is a multidimensional index of the probability of covariate shock occurring (exposure), the accumulative experience of food insecurity (sensitivity) and coping ability of households (adaptive capacity). The paper applies the index to households in southern Nigeria, using the World Bank's generalised household panel dataset. The results show $61 \%$ of households in the study to be highly vulnerable to food insecurity, $12 \%$ mildly vulnerable and $27 \%$ not vulnerable. Traditional and single indicators, such as FCS and PCC are not good indicators of vulnerability to food insecurity whereas CPI is a better indicator of vulnerability to food insecurity compared to FCS and PCC. The VFII developed in this paper includes components of FCS, PCC, and CPI and regarding ranking, the VFII was found to be reliable. Most importantly, the analysis using the VFII reveals how dietary diversity or calorie consumption indicators can exclude some households who are vulnerable to food insecurity. The paper concluded that accurately target long-term support to vulnerable households, policymakers who seek to address the underlying causes of food insecurity cannot rely on single indicators, and for this type of goal, the VFII makes a useful contribution.
\end{abstract}

Keywords: food vulnerability, vulnerability, food security, vulnerability measurement, index, 


\section{Introduction}

There has been growing concern about food insecurity crises globally, which has rekindled the interest of researchers and policymakers to provide improved disaster risk reduction planning, prediction, and targeting of support to the food vulnerable. This is a complex challenge, with over 1 billion people estimated to suffer from micronutrient deficiencies and insufficient dietary energy availability (Barrett, 2010) and a combination of factors operating across multiple scales to influence individual's food insecurity (Vaitla et al., 2017). To accurately target limited resources, better predictive models are needed that measure these subjective aspects of food security, including vulnerability (Vaitla et al., 2017). Food security definition is widely accepted as a situation that exists "when all people, at all times, have physical and economic access to sufficient, safe and nutritious food that meets their dietary needs and food preferences for an active and healthy life" (FAO, 1996). This definition emphasises the multidimensional nature of food security and any holistic model to measure food insecurity needs to reflect this. However, designing holistic models are difficult, and as a result, there is no one standard model available.

Maxwell et al. (2013) argue that single measures or indicators of food security are therefore commonly used for assessment of "access", but these consider only current access to food without a good understanding of the wider risks that households face. For example, percapita caloric intake has been used as a "gold standard" to measure food insecurity at the household level especially for rapid assessment needs (Maxwell et al., 2014). However, while per capita calorie intake will reflect current consumption, it will not reflect other more complicated elements of food insecurity, like quality, vulnerability and risks, or fluctuations and trends in consumption over time and therefore not provide an understanding of how to manage long-term or seasonal vulnerability. Moreover, using single indicator can result in underestimation and misclassification of possible food insecure households (Vaitla et al., 2017). The ease of data availability is one among many reasons why single indicators are easily used. However, the problem of underestimation and misclassification commonly associated with single indicators means that the better option is using multidimensional indicators such as VFII although this require a huge data availability.

As a result, policymakers often have incomplete information available during planning decisions. Capaldo et al. (2010) have emphasised that policy should be designed to address 
this uncertainty and provide a range of risk management options to support different household needs. This emphasis reflects the importance of including vulnerability analysis in any assessment of food insecurity. However, applying the concept of vulnerability to food insecurity assessment is relatively new, and few studies have focused on it (Bashir and Schilizzi, 2012). A standard model for vulnerability analysis in food insecurity has not yet been developed, even though different analytical methods exist (Capaldo et al. 2010). The problem is further compounded as the literature on vulnerability argues that the concept is relative and therefore difficult to measure (Hinkel, 2011; Moss et al., 2001). A further challenge is that there is no official goal for measurement, so researchers use similar but slightly different approaches for different aspects of the problem. This can lead to different interpretations of the nature of the problem and can result in policy responses that are ineffective in the long-term or exclusionary for some households.

This paper seeks to contribute to this gap in knowledge by presenting how it is feasible to develop a prototype food insecurity indicator that is based not only on current consumption, wealth or income levels but also incorporates a vulnerability dimension. This indicator is called the Vulnerability to Food Insecurity Index (VFII) and is a multidimensional index that measures household's food insecurity and vulnerability. In doing so, it considers the risk and uncertainty associated with food insecurity by reflecting on how food-related shocks influence food vulnerability for a household. The VFII also provides an improved methodology for food insecurity analyses and serves as a better tool to accurately profile vulnerable households for cost-effectively targeting of interventions. The primary objective of this paper is to present how the VFII was developed and to establish its validity, by comparison with other traditional indicators. We ask to what extent is this index better captures components of food insecurity and vulnerability as compared to traditional measures of food insecurity? The VFII can be compared with results from per capita food consumption, food consumption score and coping strategy index. An uncertainty and sensitivity analysis on the VFII can be performed to test its robustness on assumptions used in the model. The next section provides an overview of the current debate in the literature, in particular, conceptualisations used to understand and assess food insecurity and vulnerability. Section 3 outlines the methodology used, and section 4 summarises the sensitivity and robustness analysis, with sections 5 and 6 presenting the results, discussion and conclusions. 


\section{Conceptualising vulnerability to food security}

There is an extensive discourse on food insecurity and vulnerability in the literature, and this section is restricted to illustrating how these conceptualisations of vulnerability to food insecurity have guided this research, and how approaches related to these different views can be used to operationalise vulnerability.

\subsection{The value of understanding contextual vulnerability for food insecurity assessment}

Vulnerability is commonly defined as the degree to which a system is likely to experience harm due to hazards (Villagrán de León, 2006). Food vulnerability exists when food-related shocks stress a household's ability to acquire safe and nutritious food. This stress emanates from the biophysical and socio-economic systems operating across multiple scales to influence the household. Outcome vulnerability and contextual vulnerability can be explored to understand these systems, but each comes from a different focus and uses a different approach.

According to Fellmann (2012), outcome vulnerability is based within the natural sciences, most recently as a result of interest in climate change outcomes and uses future model scenario as a basis for analyses. It concerns itself primarily with biophysical changes in a closed system, with a boundary between nature and society. As a result, the role of socioeconomic components in ameliorating the effect of risk is not explicitly included. Accordingly, a system considered to be vulnerable will be that which will experience the most dramatic physical changes. Those who adopt a focus on outcome vulnerability adopt a more closed system approach in their attempts to operationalise vulnerability. For example, econometric approaches are inductive and try to use both secondary and primary data of a specific system or unit to come to conclude the level of harm (Hinkel, 2011; Singh, 2014). The use of statistical models heavily relies on the availability of data, with cross-sectional, repeated cross-sections and longitudinal data most commonly used. However, the best-suited data for micro-vulnerability analysis is panel or longitudinal data (Hoddinott and Quisumbing, 2003; Hoogeveen et al., 2004; Chaudhuri et al., 2002; Günther and Harttgen, 2009). Panel data has advantages because it gives a more precise estimation of change in 
variables means, provides accurate data on past events, is cheap to collect for selected individuals over a specific period and is suitable for fixed effect analysis, enabling the researcher to have control over time-invariant variables (Hoddinott and Quisumbing, 2008). Examples of econometric models used in vulnerability analysis include structural dynamic models (Elbers and Gunning, 2003; Scaramozzino, 2006), three-stage feasible generalized least square (Chaudhuri et al., 2002; Capaldo et al., 2010; Adepoju et al., 2011), multilevel analysis (Günther and Harttgen, 2009), Value at Risk (Scaramozzino, 2006), limiteddependent variables (Scaramozzino, 2006; Corral et al., 2015), instrumental variable estimation (Karfakis et al., 2011), generalized maximum entropy (Corral et al., 2015), and two-stage least square (Christiaensen and Boisvert, 2000). The main strength of this approach is the ability to estimate vulnerability for a future period (Elbers and Gunning, 2003) but the method is dependent on reliable panel data. According to Chaudhuri et al. (2002), panel data is not readily available in most developing countries and, when available, it often has unrepresentative cross-sectional components reducing its usefulness for policy analyses.

By contrast, taking a contextual vulnerability perspective develops an interest in multiple factors that shape the socio-ecological system and requires the researcher to adopt a multidisciplinary approach (Adger, 2006; Berkes and Folke, 1998). Contextual vulnerability therefore includes both the biophysical and assessment of the socio-economic drivers of vulnerability, including social marginalization, economic inequality, available household food and resource entitlements, the effectiveness of local and broader support institutions, economic and political systems (Cardona et al., 2012; Adger, 2006; O'Brien et al., 2007). This approach helps us to understand which social groups or regions tend to be more vulnerable to food insecurity (O'Brien et al., 2007), making this approach highly relevant to conceptually underpin the development of a more holistic vulnerability to food insecurity index. This approach can be operationalised using a vulnerability index methodology of the observable variables and uses a deductive approach. To define the state of vulnerability of a system, the index method can apply a concept, framework or model for the selection of variables. Examples include IPPC (2007) characteristics of exposure, sensitivity and adaptive capacity (IPCC 2007) and a sustainable livelihoods framework (Hahn et al., 2009b; Singh, 2014). A weakness of this approach is that the frameworks do not provide arguments for aggregation of variables and, thus, researchers resort to using different aggregation approaches to produce a vulnerability index. 
Nevertheless, this method has helped to reduce complex variables with different variability to single figure for ease of interpretation and comparing the result. Abson et al. (2012) argue that information is lost during aggregation. Despite not capturing the forward-looking aspect of vulnerability, it is applied as a development and adaptation planning tool (Hahn et al., 2009b). The index method can be used to construct vulnerability maps, offering guidance about areas needing either urgent response or longer-term support to reduce vulnerability to food insecurity. These maps of hotspots reflecting locations with high exposure and sensitivity but adaptive capacity (de Sherbinin et al., 2014).

\subsection{Household vulnerability to food insecurity}

The vulnerability of a household to food security can be understood as its exposure, sensitivity and adaptive capacity (IPPC, 2007; McCarthy et al., 2001; Antwi-Agyei et al., 2012) (Figure 1). Exposure refers to food-related shocks that affect household access to safe and nutritious food and is widely defined as the degree to which a system faces risk, shock or hazard (Antwi-Agyei et al., 2012; Fellmann, 2012; IPPC, 2001). When shocks occur, these affect different levels of a system. A covariate shock has the same effect across households, community or a nation while an idiosyncratic shock can occur at the household level and the effect may differ from one household to another (Lovendal and Knowles, 2005). Foodrelated shocks threaten household food availability. For instance, the frequency and intensity of a drought or flood can threaten food supply and trigger food crisis for households. 


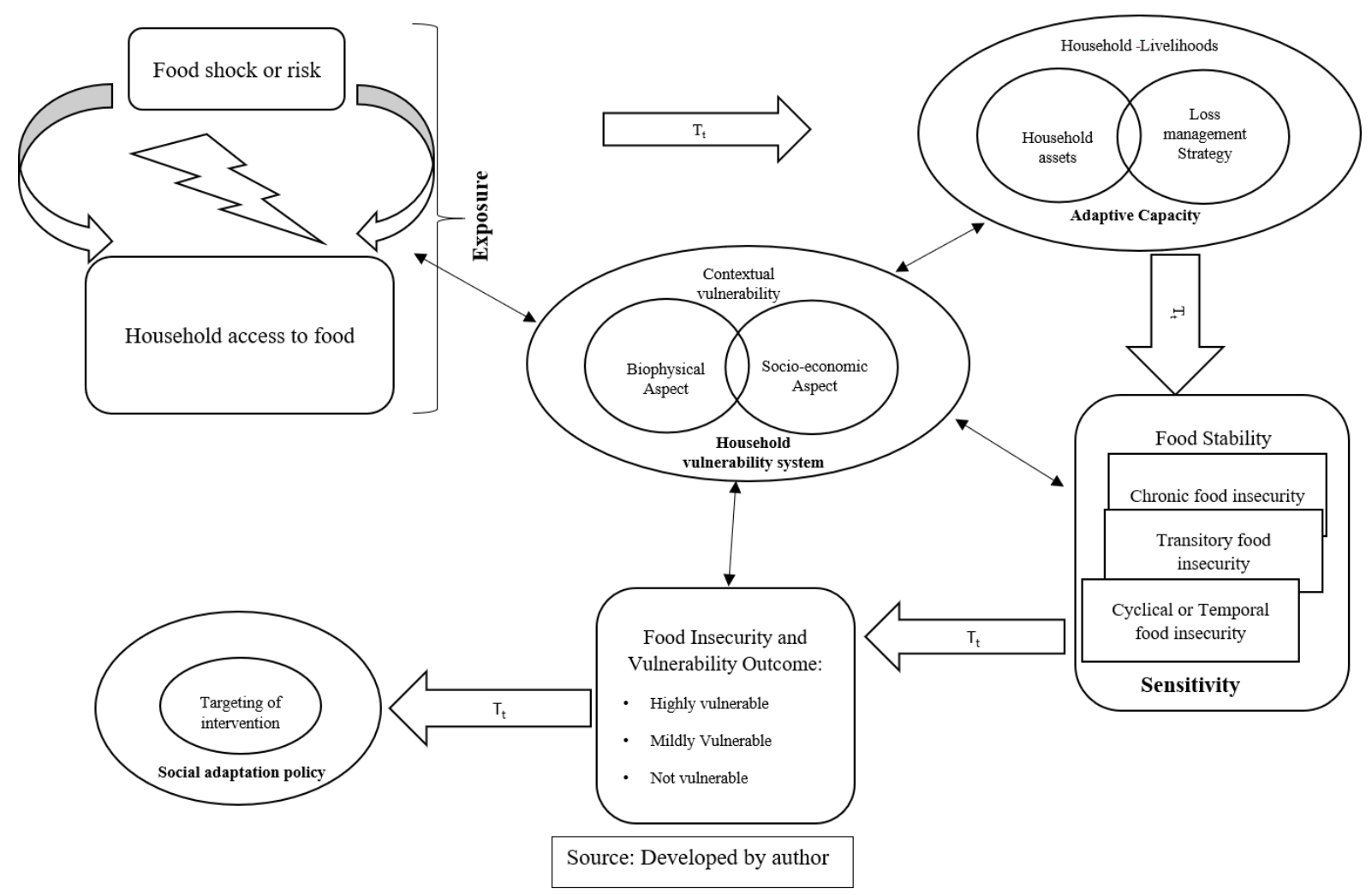

The occurrence of food-related shocks causes households to make use of their assets and initiate a series of loss management strategies to improve their household food security. Using a vulnerability lens, the ability of the household to respond is referred to as its adaptive capacity. We define adaptive capacity as the ability of households to successfully adjust to the effect of food-related shocks through coping mechanisms (Engle, 2011). A household with high adaptive capacity will likely stand a better chance of adjusting to food vulnerability. Adaptive capacity is widely accepted as a positive attribute in reducing the vulnerability of a system (Polsky et al., 2007; IPPC, 2007). Of course, households when exposed continuously to shocks; they make use of the assets to manage the stress induced by the shock. Households with more assets and better livelihood opportunities generally translate into those with greater long-term food security (Woller et al., 2013). Households who can use only a small portion of their available assets will retain their ability to respond to future challenges.

In contrast, already impoverished and food insecure households may need to make use of a more significant proportion of available assets yet may still fail to secure adequate access to food. If assets and means of livelihood cannot manage the shock, households begin to employ 
more desperate coping mechanisms. Over time this causes households to move in and out of distinct levels of food insecurity such as chronic, transitory, cyclical or temporal food insecurity. In the food security literature, these cascades of food insecurity can be considered as the level of food stability, and in the vulnerability literature, this is referred to as sensitivity. Sensitivity in this context can mean the underlying vulnerability of a household to be able to respond as a result of food shocks (Fellmann, 2012). It is also considered the degree of responsiveness of a system to stress (IPPC, 2001). The component of sensitivity represents the first order effect of food shocks in households (Hahn et al., 2009b; AntwiAgyei et al., 2012) and the sensitivity component can be used in a vulnerability to food insecurity index to mean previous or accumulative experience of food insecurity, such as stunting, child mortality, and hunger within the household. For example, undernourished mothers can give birth to children with low birth weight, while malnourished children tend to experience reduced cognitive ability, which affects their educational attainment. Adopting this understanding avoids the confusion commonly found in vulnerability literature on the distinction between adaptive capacity and sensitivity.

Finally, the response of a household to a shock will lead to several outcomes in the food vulnerability continuum. This outcome can be used to classify households into different groups of food vulnerability. These groups are households that are highly vulnerable to food insecurity, mildly vulnerable households and households that are not vulnerable to food insecurity.

Taking a contextual vulnerability approach and drawing on the framework of vulnerability to food insecurity determined through indicators of exposure, adaptive capacity, and sensitivity, we seek to determine how better to operationalise a multi-dimensional index.

\section{Methodology}

In this section, we present the design of the vulnerability to food insecurity index (VFII), the redefined exposure component and how traditional indicators of food insecurity were used to compare the strength and weakness of the new composite index. We also briefly present the uncertainty and sensitivity analysis performed on the VFII.

\subsection{Construction of the Vulnerability to Food Insecurity Index}


The conceptual framework for household vulnerability to food insecurity was applied (as outlined in section 2) to design a VFII that has three main components: exposure, sensitivity and adaptive capacity. Using panel data from the Nigerian Living Standard Measurement Survey (NBS, 2015; NBS and LSMS, 2015; World-Bank and NBS, 2015; World-Bank and NBS, 2014), indicators and variables were selected based on the components from the framework. Table 1 categorises the VFII components and related indicators from the Nigerian Living Standard Measurement Survey. Further details of these indicators can be found in Table C, located in Appendix A.

After selecting each variable to represent an indicator as shown in Table 1, we proceeded to normalize these variables.

Table 1: Indicators and variables used for the Vulnerability to Food Insecurity Index

\begin{tabular}{|c|c|c|}
\hline Index Dimension & Indicators & Description of variables \\
\hline \multirow{7}{*}{$\begin{array}{l}\text { Exposure } \\
\text { (probability of } \\
\text { covariate shocks } \\
\text { occurring) }\end{array}$} & Health shock & Illness of income earning member \\
\hline & Unemployment shock & Job loss \\
\hline & \multirow[t]{2}{*}{ Civil conflict shock } & Theft of crops, cash, livestock or other \\
\hline & & Kidnapping/Hijacking/robbery/assault \\
\hline & \multirow[t]{2}{*}{ Agro-climatic shock } & Poor rain that caused harvest failure \\
\hline & & Flooding that caused harvest failure \\
\hline & Food price shock & Increase in price of major food items consumed \\
\hline \multirow{3}{*}{$\begin{array}{l}\text { Sensitivity } \\
\text { Previous/accumulative } \\
\text { experience of food } \\
\text { insecurity }\end{array}$} & Malnutrition & Length/height-for-age (stunting) \\
\hline & Child mortality & Total number of children dead in each household \\
\hline & Hunger & $\begin{array}{l}\text { Total number of days' households gone without eating } \\
\text { any food. }\end{array}$ \\
\hline \multirow{11}{*}{$\begin{array}{l}\text { Adaptive Capacity } \\
\text { how household } \\
\text { respond, exploit } \\
\text { opportunities, resist or } \\
\text { recover from food } \\
\text { insecurity shocks }\end{array}$} & \multirow[t]{4}{*}{ Wealth Index } & Household assets used to assess information \\
\hline & & Mobility assets used in households \\
\hline & & Livelihood assets own by households \\
\hline & & Housing structure characteristics \\
\hline & \multirow[t]{3}{*}{ Access to infrastructure } & Household distance to nearest major road $(\mathrm{km})$. \\
\hline & & Household distance to nearest market $(\mathrm{km})$. \\
\hline & & $\begin{array}{l}\text { Time taken to walk one way to the water source from } \\
\text { household dwelling (minutes). }\end{array}$ \\
\hline & \multirow[t]{3}{*}{ Livelihood activities } & $\begin{array}{l}\text { Total income from savings, rental of properties and } \\
\text { other types of income. }\end{array}$ \\
\hline & & Estimated revenue from non-farm enterprises \\
\hline & & Total yield of crops harvested $(\mathrm{kg})$ \\
\hline & Household literacy & $\begin{array}{l}\text { Cumulative years of schooling for household heads or } \\
\text { closest individual }^{1} \text { in the household. }\end{array}$ \\
\hline
\end{tabular}

${ }^{I}$ This is the next individual in the household if education is missing for the household head, who has the highest level of education, and at least five years of schooling. If educational qualifications are the same for more than one individual, the most senior individual in age is used.

We normalised variables to ease comparison and for all variables to have an equal unit (OECD, 2008). We used the min-max normalization method shown in equation 1. 


$$
I_{V F I I}=\frac{X_{f v i}-X_{\min }}{X_{\max }-X_{\min }} \ldots \ldots \ldots \ldots \ldots[1]
$$

Where $X_{\max }$ and $X_{\min }$ are the minimum and maximum values of the normalised vulnerability to food insecurity index $\left(I_{V F I I}\right)$ and having the values lying between 0 (laggard) and 1 (leader), respectively (UNDP, 2007; Hahn et al., 2009b; OECD, 2008; Singh, 2014; Freudenberg, 2003).

The next step we generated a weight for these variables. Four methods exist in literature that is used to assign weight to variables: by quality of data (OECD, 2008), expert opinion (Brooks et al., 2005; Malcomb et al., 2014; de Sherbinin, 2014; Singh, 2014), equal weighting (Lucas and Hilderink, 2005) and statistical method such as principal component analysis (Gbetibouo et al., 2010; Madu, 2012). We used both equal weights and unequal weight (using principal component analysis) for the VFII variables (for detail discussion on weights applied in this paper see Appendix B). However, after performing uncertainty and sensitivity analysis, we adopted equal weight for the index (see Appendix B). So, each component of the VFII was assigned equal weights.

Finally, to compute the VFII score we used the aggregation method shown in equation 2. Where $E_{i}$ is the exposure index, $S_{i}$ is the sensitivity index and $A C_{i}$ is adaptive capacity index.

$$
V F I I_{i}=\sum A C_{i}-\left(\sum E_{i}+\sum S_{i}\right)
$$

Households with lesser and negative VFII composite values are more vulnerable to food insecurity compare to households with higher and positive VFII composite scores. In other words, the higher the composite value of VFII, the lower the vulnerability impact on household food security.

\subsection{VFII threshold}

A household can be highly exposed or sensitive to food insecurity, but this is not a sufficient condition to say that this household is vulnerable to food insecurity. Thus, a vulnerable household is one in which their adaptive capacity is too low to help such household adjust successfully to the stress caused by exposure and sensitivity. We defined our VFII threshold as a point where household adaptive capacity is higher than the combined effect of exposure and sensitivity. Given that the VFII has three components which are equally weighted, each 
component has a weight of 0.33 . In other words, each component represents $1 / 3$ dimension of vulnerability.

Mathematically, when:

- $(\mathrm{E}+\mathrm{S})>\mathrm{AC}$, such household is said to be vulnerable to food insecurity

- $(\mathrm{E}+\mathrm{S})<\mathrm{AC}$, such household is not vulnerable to food insecurity

From the understanding of this mathematical notation, at what point can we say that a household is vulnerable or not vulnerable to food insecurity using our VFII composite score? A household will be at two points:

- First, is when a household VFII composite score is less than $1 / 3$ mean of total VFII composite score for all households. At this point, a household is severely vulnerable to food insecurity.

- Second, is when a household VFII composite score is less than 2/3 mean of total VFII composite score for all households and greater than 1/3 mean of total VFII composite scores. At this point, a household is vulnerable to food insecurity (Table 2).

Using this threshold method will provide a cut-off point that is meaningful and reflect different vulnerability stories from the sample bearing in mind that vulnerability is context and place specific. Using the aggregation method in equation 2 to compute our VFII, the index composite score responds to positive values, and the magnitude is in ascending order. That is vulnerability ranges from a positive value to a negative value. The more positive the score, the less the households are vulnerability to food insecurity and vice versa. We then used this score to categorise households into three different food vulnerability groups. The first group are households that are highly vulnerable to food insecurity. These are households in dire and worst level of food insecurity and vulnerability, and their composite score is less than or equal to -0.0530 (see Table 2). The next group are households that are mildly vulnerable to food insecurity. Their composite score is higher than -0.0530 but less than 0.0265. The last group are households that are not vulnerable to food insecurity. The composite score is higher than -0.0530 .

Table 2: Threshold for VFII, FCS, CPI and PCC

\begin{tabular}{lllll}
\hline $\begin{array}{l}\text { Food security } \\
\text { Indicators }\end{array}$ & Classification & Description & Range & Remark \\
\hline \multirow{2}{*}{ VFII } & 1 & Highly vulnerable & $<=-0.0530$ \\
& 2 & Mild vulnerable & $>-0.0530 \&<-$ & $\begin{array}{l}\text { The higher the } \\
\text { score, the better }\end{array}$ \\
& 3 & Not vulnerable & $>0.0265$ & \\
\hline & 1 & Poor & $0-28$ & The higher the \\
\hline
\end{tabular}




\begin{tabular}{|c|c|c|c|c|}
\hline \multirow[t]{2}{*}{ FCS } & 2 & Borderline & $28.5-42$ & \multirow[t]{2}{*}{ score the better } \\
\hline & 3 & Acceptable & $>42$ & \\
\hline \multirow{4}{*}{ CPI } & 1 & Least severe & $0-2$ & \multirow{4}{*}{$\begin{array}{l}\text { The lower the } \\
\text { scores, the } \\
\text { better }\end{array}$} \\
\hline & 2 & Moderately severe & $3-12$ & \\
\hline & 3 & Severe & $13-40$ & \\
\hline & 4 & Most severe & $>40$ & \\
\hline \multirow[b]{2}{*}{ PCC } & 0 & Poor consumption & $<2360 \mathrm{kcal} /$ day & \multirow{2}{*}{$\begin{array}{l}\text { The higher the } \\
\text { score the better }\end{array}$} \\
\hline & 1 & $\begin{array}{l}\text { Acceptable } \\
\text { consumption }\end{array}$ & $>=2360 \mathrm{kcal} /$ day & \\
\hline
\end{tabular}

\subsection{Redefining the exposure component of the VFII}

The exposure as define by IPPC (2007) is the occurrence of shocks that affect household food security. Invariably, this component of food vulnerability index is mostly characterised by its intensity and duration (Krishnamurthy et al., 2014). One weakness of this definition is that the occurrence of a shock does not necessarily mean that it could be used as an indicator of exposure for a given geographical area. For example, the occurrence of malaria in a household does not necessarily indicate that households in this area are more exposed to malaria. Because of this, we redefine exposure to mean the probability of occurrence of a shock. Consider that a household is standing on a precipice (precarious state of food insecurity), the exposure, in respect to this scenario is the probability of this household receiving a shock or a push which could further lead to a major fall into a more dangerous food security situation. Using this concept, the exposure variables used in this research is rather from the enumeration area (community level) and not the household level. In other words, the research derived exposure from household data by looking at the proportion of households in each enumeration area that report that they have been affected by the occurrence of selected shocks in the past five years. The shock with the highest percentage is now used for that enumeration area. For examples, if $50 \%$ of households in Abak (an enumeration area in Akwa Ibom state) reported that they had been most affected by an increase in prices of major food commodities consume, then households in this area is prone to food price shocks. Thus, using this information, all households in this area are given the value of $50 \%$ to represent food price shock irrespective of that fact that they might or might not experience this shock. The reason for doing this is because there is no macroeconomic data on the prevalence of selected shocks used in this research. 


\subsection{Data}

The dataset used for this research is General Household Survey Panel (GHS-Panel), which is a Living Standard Measurement Study (LSMS) survey from the World Bank. The dataset contains a panel component (GHS-Panel) which is a randomly selected sub-sample of 5,000 households from a cross-sectional survey of 22,000 households carried out annually throughout Nigeria. The dataset contains information on human capital, economic activities, access to services and resources, food security and additional information on agricultural activities and household's consumption are collected from the panel households. As at the time this research was carried out, the GHS-Panel had two waves: the first wave (20102011) and second wave (2012-2013). In each wave, visits are carried out within two periods to panel households. The first period is the post-planting visit in August-October 2010 (wave 1) while September - November 2012 (for wave 2) and the second period is the post-harvest visit in February-April 2011 \& 2013 for both waves respectively. A onetime visit is carried out for the cross-section along with the post-harvest visit to the panel households (NBS, 2015; NBS and LSMS, 2015; World-Bank and NBS, 2015; World-Bank and NBS, 2014; Corral et al., 2015). We made use of both wave 1 and wave 2 datasets in designing the Vulnerability to Food Insecurity Index. Although the VFII uses 21 variables, all the data for these variables are from the panel component of World Bank LSMS survey data set. The LSMS are standardize data set which is increasingly available for many developing countries. The availability of LSMS data across many developing countries mean that the VFII can be applied to these countries while comparing result overtime.

\subsection{Construction of other traditional food security indicators}

In this section, we discuss the methods used in designing per capita calories consumption, food consumption score and coping strategy index.

\subsubsection{Food energy consumed per capita (Per capita calories consumption)}

Food energy consumption is an indicator that measures the total dietary quantity of food energy consumed in each household. Energy in food is vital for survival, performing physical activities and for survival. This indicator measures the sufficiency of energy available in food eaten by households and also used to indicate the ability of households to have access to food (Dary and Imhoff-Kunsch, 2010; Smith and Subandoro, 2007). The following procedures were used to compute this indicator. All non-standardized food quantities recorded in the 
household dataset were converted from the local unit (e.g. bunch or rubber) to standardise unit in grams. By multiplying the quantities of local food items by their metric weight. The household survey data set provided the Metric weight for each food item. Food items with missing weight were removed. The total energy content of food acquire by each household was derived using the following equation, total food energy (kilocalories) = Food quantity in grams per day * edible portion * (food energy conversion factors/100). The energy conversion factor of food items was gotten from FAO et al. (2012), and FAO (1968). Finally, total daily calorie availability per adult equivalent for households was computed by dividing total energy acquisition per household per day by adult equivalent factor. Using multiple imputation techniques, an OLS regression with the independent variables that are household's characteristics was used to compute missing calorie availability for households that had this data missing. The FAO recommends an average food consumption of 2360 $\mathrm{kcal} /$ person/day; this value was used as the threshold score for households in this study.

\subsubsection{Food Consumption Score (FCS)}

FCS is a food security indicator developed by the World Food Program that measures the dietary diversity of food consumed in the households with a seven days recall period (Vaitla et al., 2017). It is possible for a household to meet their food energy requirement but could not leave a healthy and active life because of deficiency of other macronutrient (like protein) and micronutrients such as iron, vitamin A, and iodine (Smith and Subandoro, 2007). Hence, FCS monitor changes in food nutrition within the households (Jones et al., 2013b). It is a composite index that is made up of 9 weighted food groups. The weight attached to each food groups are: cereals and tuber $=2$, pluses $=3$, vegetables $=1$, fruit $=1$, meat and fish $=4$, milk $=4$, sugar $=0.5$, oil $=0.5$ and condiments $=0$. The frequency of each food group consumed is multiplied by the assigned weight; the scores obtained now sum to get the FCS for each household. The overall score range between 0 -112. There two threshold categories are given by WFP for grouping households: a household with oil and sugar consume daily and household that does not consume oil and sugar daily. This study adopted the threshold for households that consume oil and sugar. Households with FCS above 42 are considered acceptable, scores between 28.5 - 42 are borderline, and scores within 0-28 are poor food consumption (Maxwell et al., 2014; Vaitla et al., 2017). 


\subsubsection{Coping Strategy Index (CSI)}

The CSI measures the frequency and severity of specific behaviours employed by households when there is a food deficit. The CSI measure both current food security situation and is a good predictor of future food vulnerability of households (Maxwell and Caldwell, 2008). To compute the CSI, the frequency of coping strategy used by households is multiplied by the weight. The weight ranges from 1 (least severe category) to 4 (most severe coping behaviour). The coping strategies and weight are: borrowing food or rely on friends or relatives (2), limits the variety of foods eaten (3), reduce number of meals eaten in a day (3), limit portion size at meal-times (4), restrict consumption by adults in order for small children to eat (4), have no food of any kind in the house (4), sleep hungry at night because of no food (4), and go a whole day and night without eating anything (4). The weighted frequencies then sum to derive the CSI score. There is no universal guideline to interpret the CSI score. However, Maxwell et al. (2014) suggested scores within 0-2 (food secure), 3-12 (mildly food insecure), 13-40 (moderately food insecure), and above 40 (severely food insecure).

\subsection{Uncertainty and Sensitivity}

We carried out an uncertainty and sensitivity analysis to evaluate the robustness of the VFII. We evaluated how serval assumptions used in the index construction could have an impact on its output. A summary of the uncertainty and sensitivity analysis result is present in the next section (Section 4). See Appendix B to read the full paper.

\section{Sensitivity and Robustness}

We systematically investigated the effect of some methodological assumptions on the robustness of Vulnerability to Food Insecurity Index. The focus was to examine how alternative data type, weight scheme, normalisation method and exclusion/inclusion of variables affect the index using uncertainty and sensitivity analysis. We used two approaches: One-at-a-time and global sensitivity approach for the analysis. Using one-at-a-time approach, we explore how the VFII output response to alternative data type, different weighting scheme, normalisation method and inclusion/exclusion of variable. For the global approach (Saltelli, 2017), we used Sobol' first-order index and total effect index to explore the uncertainty and sensitivity of VFII (Sobol', 1967). The result of the robustness analysis indicated that VFII performance is stable to changes in the variables and normalisation method when equal weight is applied. Using the min-max normalisation method produces 
highly robust estimate than $\mathrm{z}$-score. Hence, we adopted equal weight and min-max normalisation method for the VFII. The main input factor that influenced the variance of VFII output is the shock variable. This means that the VFII is highly sensitive to shock, therefore better capturing the vulnerability component of food security. We conclude that the index is fit for purpose and will perform better than other indicators of food security in terms of vulnerability. For detail explanation of the uncertainty and sensitivity see Appendix $B$.

\section{Application and Discussion}

In this section, we applied our methodology to households' dataset in the South-South region of Nigeria and discussed the result. Specific results presented in this section are: descriptive statistics result; distribution of households in terms of VFII, CPI, FCS and PCC; the relationship between indicators, the proportion of households classified into different food vulnerability group by FCS, PCC, and CPI; and ranking of states by VFII.

\subsection{Descriptive statistics}

The descriptive statistics result for the data used in the construction of Vulnerability to Food Insecurity Index is presented in Table 3 and Table 4. In Table 3, South-South region of Nigeria, about $25 \%$ which are the majority of households are exposed to high food price shocks. Other shocks that households experience according to their magnitude are: theft of crops, cash and livestock (21\%), illness of income earning member (13\%), loss of job (11\%), poor rain that caused harvest failure $(8 \%)$, flooding that caused harvest failure $(6 \%)$ and kidnapping (1\%). About $15 \%$ of households did not experience any of these shocks as at the time the data were collected.

On average, the $\mathrm{z}$-score for length/height-for-age (stunting) for children within 0-60 months in households is 1.068 (Table 4). Approximately, one child died on average, and household stayed for at least 5 hours per day without any food on average. The average distance to the nearest major road is $11.05 \mathrm{~km}$, nearest market is $62.51 \mathrm{~km}$, and it will take 24 minutes on average for households to walk one way to the nearest water source. The estimated revenue for a household that had non-farm revenue is $-34,146.3$ naira and total revenue from savings/rental of properties is 91,110.39 naira on average. The total yield of harvested crops for households that had farm is $1,510.41 \mathrm{~kg}$. On average household heads or closest individual had 9.12 years of schooling. The wealth index composite score is -0.49 on average. 
Table 3: Shocks that affected households

\begin{tabular}{|l|l|l|}
\hline Shocks & Frequency & Percent \\
\hline Flooding & 50 & 6.25 \\
\hline Food price & 200 & 25 \\
\hline Illness & 100 & 12.5 \\
\hline Job loss & 90 & 11.25 \\
\hline Kidnapping & 10 & 1.25 \\
\hline None & 120 & 15 \\
\hline Poor rain & 60 & 7.5 \\
\hline Theft & 170 & 21.25 \\
\hline Total & 800 & 100 \\
\hline
\end{tabular}

Source: Data analysis

Table 4: Descriptive statistics of VFII variables

\begin{tabular}{llll}
\hline Variable & Observation & Mean & Std.Dev. \\
\hline Stunting & 800 & 1.068462 & 5.676223 \\
Child mortality & 800 & 0.53 & 1.35606 \\
Hunger & 800 & 0.20625 & 0.752941 \\
Wealth Index & 800 & -0.49638 & 2.892449 \\
Distance-to-road & 800 & 11.04825 & 13.26008 \\
Distance-to-market & 800 & 62.50875 & 37.52519 \\
Distance-to-water & 800 & 23.89885 & 65.63988 \\
source & & & \\
Income-from-Savings & 800 & 91110.39 & 137746 \\
Non-farm business- & 459 & -34146.3 & 169359.7 \\
income & & & \\
Crop yield (KG) & 391 & 1510.411 & 2726.564 \\
Household literacy & 800 & 9.12 & 4.963002 \\
\hline
\end{tabular}

Source: Data analysis 


\subsection{What is the distribution of poor/non-poor households in terms of VFII,}

CPI, FCS, and PCC?

The distribution of households by VFII and other traditional indices we used in this paper are shown in Table 5, Table 6, Figure 2 and Figure 3. The Vulnerability to Food Insecurity Index (VFII) result showed that $61 \%$ of households in the study are highly vulnerable to food insecurity, $12 \%$ are mildly vulnerable and $27 \%$ are not vulnerable to food insecurity (Table 5 ). About $73 \%$ of households is the proportion that is vulnerable to food insecurity although the category of vulnerability differs. Coping strategy index (CPI) result for post-planting and post-harvest households are presented in Figure 2. The result indicates that majority of the households (33.77\%) used severe coping strategy while $29.47 \%$ used least severe coping strategy when there is food deficit during the post-planting season. The reverse is the case during the post-harvest season. During this period majority of households used least severe $(43.22 \%)$ and moderately severe $(25.13 \%)$ coping strategy when there is food deficit.

The food consumption score (FCS) in Table 6 showed that $86.78 \%$ of households had an acceptable level of food consumption, $10.55 \%$ had borderline, and only $2.67 \%$ had poor consumption. The FAO recommended average dietary energy intake for Nigeria is 2360 $\mathrm{kcal} /$ person/day. We used this threshold as our cut-off point our per capita calorie consumption (PCC). In Figure 3, the result shows that $75 \%$ of households had poor calories consumption. In other words, these households had consumed less than $2360 \mathrm{Kcal} /$ day after adjusting for adult equivalent. Only $25 \%$ of households had consumed either exactly or above the recommended level of calories per day. 
Table 5: Distribution of food insecurity and vulnerability in South-South Nigeria

\begin{tabular}{|l|l|l|}
\hline VFII categories & Frequency & Percent \\
\hline $\begin{array}{l}\text { Highly } \\
\text { Vulnerable }\end{array}$ & 487 & 60.88 \\
\hline Vulnerable & 100 & 12.5 \\
\hline Not vulnerable & 213 & 26.63 \\
\hline Total & 800 & 100 \\
\hline
\end{tabular}

Source: Data Analysis

Figure 2: Coping Strategy Index distribution for households in South-South Nigeria

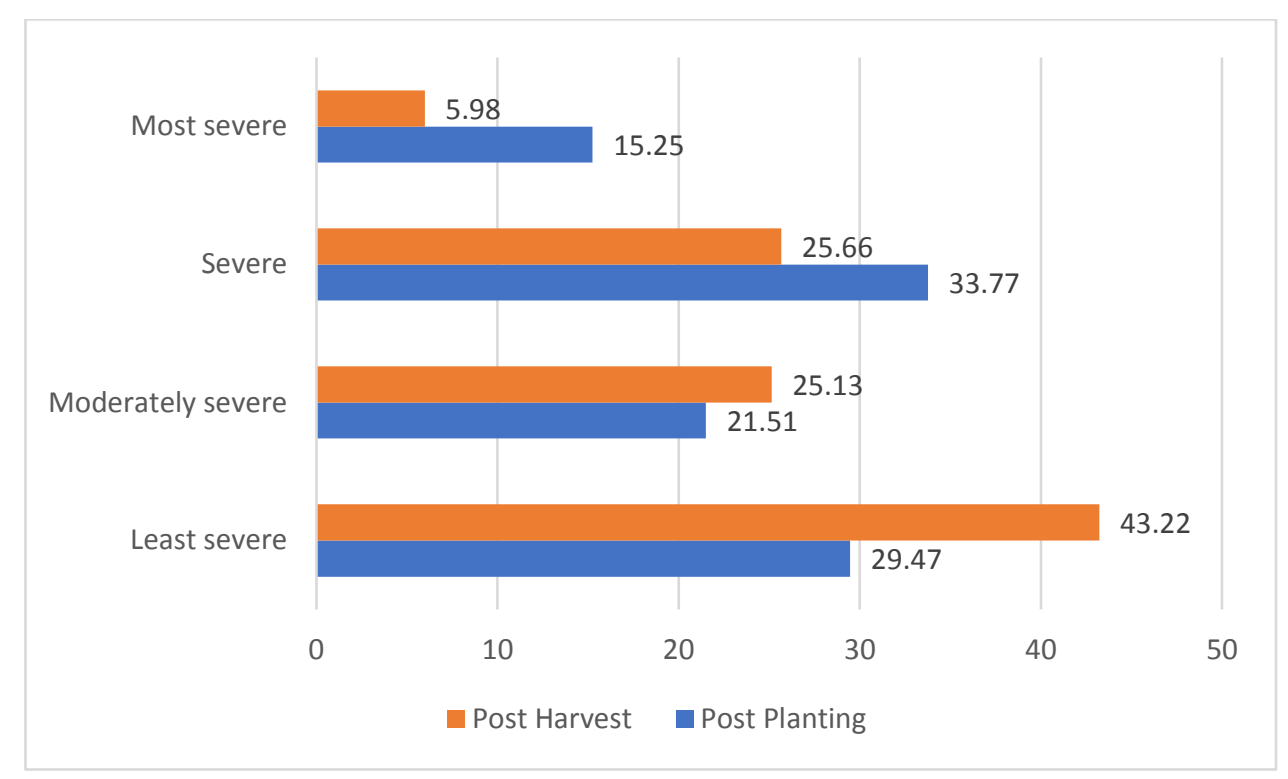

Source: Data analysis 


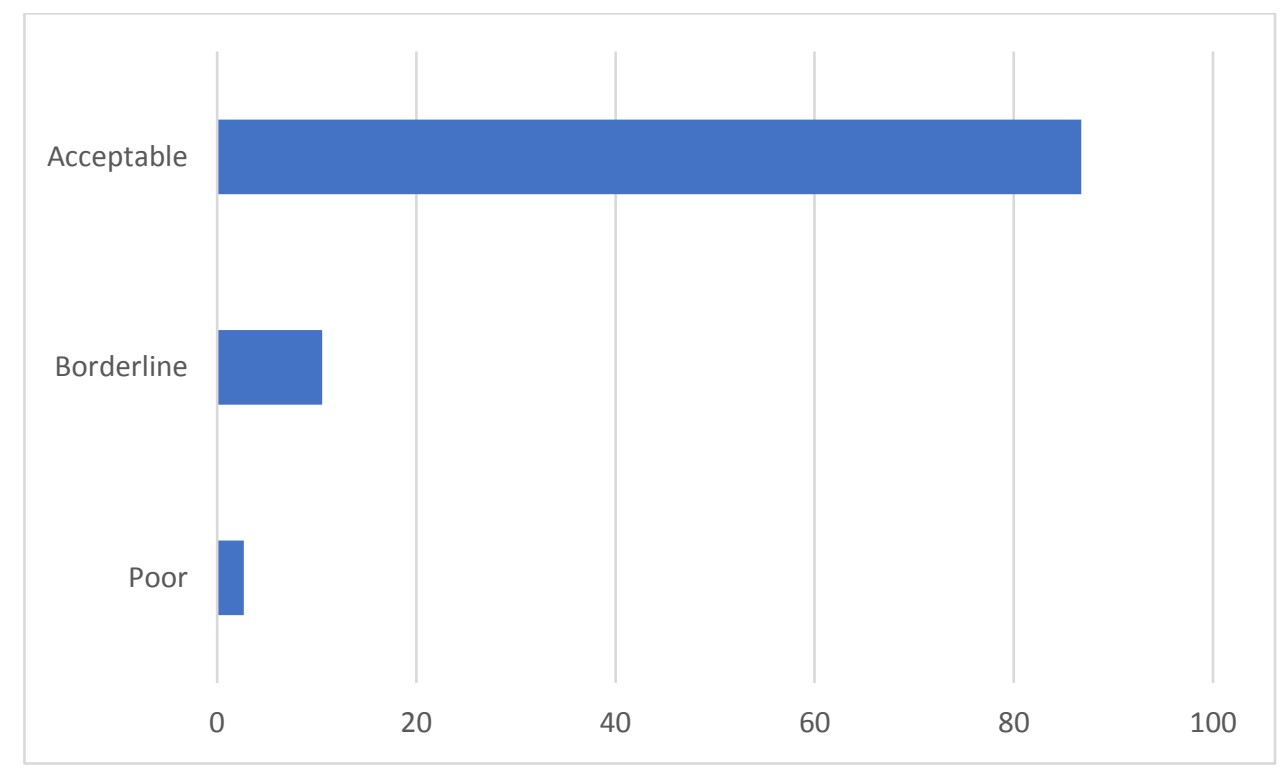

Source: Data Analysis

Table 6: Per capita calories consumption distribution of households in South-South Nigeria

\begin{tabular}{|l|l|l|}
\hline $\begin{array}{l}\text { Per capita calories } \\
\text { consumption Categories }\end{array}$ & Frequency & Percent \\
\hline Poor Calories consumption & 597 & 74.63 \\
\hline $\begin{array}{l}\text { Acceptable Calories } \\
\text { Consumption }\end{array}$ & 203 & 25.38 \\
\hline Total & 800 & 100 \\
\hline
\end{tabular}

Source: Data Analysis

5.3 Are FCS, CPI and PCC good indicator of vulnerability to food insecurity?

\subsubsection{Relationship between VFII, FCS, CPI and PCC}

We present in Table 7 the correlation result between Vulnerability to Food Insecurity Index, coping strategy index (both post planting and post-harvest season), and per capita calories consumption. We present the correlation result using three different correlation analyses, but only the Pearson coefficient will be discussed because it has the highest correlation coefficient. All the results are from the first wave data except for per capita calorie consumption which we used the second wave data. This is because we had extremely high values of calories after estimating calories form the first wave data. They were two main reasons for this - measurement errors and no standardise unit for converting some local unit. 
FCS and VFII are weakly correlated with a coefficient of 0.11 but highly significant at $1 \%$. This implies that there is a positive relationship between FCS and VFII. Weak correlation of 0.11 implies that FCS and VFII measure two different phenomena that are not closely related although they are in the same dimension of food security. This means that food vulnerability is more than households eating diversify food only.

We see a different result with the coping strategy index. We only discuss the CPI for postharvest household because of it significant at $10 \%$ level. The relation between VFII and CPI for post-harvest households is negative. There is an inverse relationship between VFII and CPI, and this agrees with apriori expectation. It, therefore, means that in the post-harvest season vulnerability to food insecurity tend to decrease as food is readily available. Alternatively, the result shows that as households employ least severe coping strategy, their vulnerability to food insecurity decreases whereas using highly severe coping strategy will increase the chances of households being vulnerable to food insecurity.

The relationship between VFII and per capita calorie consumption (PCC) is highly significant at $1 \%$ level. There is a positive association between VFII and PCC. However, the correlation coefficient value of 0.15 shows that the relationship is not a perfect one. The relationship between VFII and PCC account for only $15 \%$ variation. This means that several other factors contribute to household's vulnerability to food insecurity. It is commonly assumed that households that are not vulnerable to food insecurity should be consuming sufficient calories per day. However, this result shows that consuming sufficient calories is not enough to overcome vulnerability to food insecurity. Because vulnerability to food insecurity requires more than consuming adequate calories.

In summary, FCS and PCC are not able to reflect multi-dimensional concept like vulnerability to food insecurity whereas to a certain level, CPI better reflect the concepts of vulnerability to food insecurity.

Table 7: Correlation result between VFII, FCS, CPI, and PCC VFII

Indicator Pearson Spearman Kendall Tau-a Kendall Tau-b




\begin{tabular}{lllll}
\hline FCS & $0.1180 * * *$ & $0.1190 * * *$ & $0.0807 * * *$ & $0.0810 * * *$ \\
CPI_PH & $-0.0744 *$ & $-0.0952 *$ & $-0.0627 * *$ & $-0.0678 * *$ \\
CPI_PP & -0.0409 & $-0.0653 *$ & $-0.0443 *$ & $-0.0459 *$ \\
PCC & $0.1530 * * *$ & $0.1435 * * *$ & $0.0944 * * *$ & $0.0944 * * *$ \\
\hline
\end{tabular}

Source: Data Analysis

5.3.2 Proportion of households that are classified into different groups of vulnerability to food insecurity by FCS, PCC, and CPI

We went further to investigate the proportion of households that are classified into different groups of food vulnerability by FCS, PCC, and CPI. In Table 8, we observed that majority (51.27\%) of households that are classified as highly vulnerable to food insecurity by VFII had an acceptable level of food consumption. In other words, the majority of highly vulnerable households consumed highly diversify food. This further proves that FCS is not consistent in classifying households that are vulnerable to food insecurity. In contrast, VFII can pick some elements of dietary diversity, because most households $(23.77 \%)$ that were not vulnerable to food insecurity had consumed highly diversify food. This situation also holds for per capital calories consumption in Table 9. Majority of the households (17.88\%) that are either highly vulnerable or vulnerable to food insecurity had consumed above the recommended per capital calorie. However, it is expected that households with adequate per calorie consumption should not be vulnerable to food insecurity, this was not the case. Also, Table 6 showed that majority of the households (19.13\%) that were not vulnerable to food insecurity had poor calorie consumption. Again, strengthening our argument that single indicators like PCC is inconsistent in identifying households that are vulnerable to food insecurity. In Table 10, the result shows that $32.33 \%$ of households that are highly vulnerable to food insecurity used severe coping strategy during the post-planting season. It is expected that households that are vulnerable to food insecurity should be using adverse coping strategy to secure food during a time of food deficit. The reverse is the case for households that were not vulnerable to food insecurity. Majority of households that were not vulnerable to food insecurity (14.21\%) used the least coping strategy during the post-planting season. Here, there is a bilateral relationship between CPI and VFII. This means that the CPI better captures and in is consistent in identifying households that are vulnerable to food insecurity compare to FCs and PCC. It further proves that our VFII can pick a component of CPI even though we used different indicators and method in their design. The result of CPI for post- 
harvest households shows that across all groups of VFII, households used the least coping strategy during the post-harvest season (Table 11).

In summary, our VFII can pick some component of FCS, PCC, and CPI. However, FCS and PCC are inconsistent when used for identifying households that are vulnerable to food insecurity. CPI betters capture food vulnerability issues compare to FCS and PCC.

Table 8: VFII and FCS

\begin{tabular}{lllll}
\hline \multicolumn{5}{c}{ Food Consumption Score (\%) } \\
\hline VFII groups (\%) & Poor & Borderline & Acceptable & Total \\
\hline Highly & 2 & 8.14 & 51.27 & 61.42 \\
Vulnerable & & & & \\
Vulnerable & 0.27 & 0.93 & 11.75 & 12.95 \\
Not vulnerable & 0.4 & 1.47 & 23.77 & 25.63 \\
Total & 2.67 & 10.55 & 86.78 & 100 \\
\hline
\end{tabular}

Source: Data analysis 
Table 9: VFII and PPC

\begin{tabular}{|c|c|c|c|}
\hline \multicolumn{4}{|c|}{ Per capita calorie consumption (\%) } \\
\hline VFII groups (\%) & Poor consumption & $\begin{array}{l}\text { Above recommended } \\
\text { level }\end{array}$ & Total \\
\hline Highly & 47.63 & 13.25 & 60.88 \\
\hline \multicolumn{4}{|l|}{ Vulnerable } \\
\hline Vulnerable & 7.88 & 4.63 & 12.5 \\
\hline Not vulnerable & 19.13 & 7.5 & 26.63 \\
\hline Total & 74.63 & 25.37 & 100 \\
\hline
\end{tabular}

Source: Data Analysis

Table 10: VFII and CPI for post-planting households

\begin{tabular}{|c|c|c|c|c|c|}
\hline \multirow[b]{2}{*}{ VFII groups } & \multicolumn{5}{|c|}{ CPI for post-harvest households (\%) } \\
\hline & $\begin{array}{l}\text { Least } \\
\text { severe }\end{array}$ & $\begin{array}{l}\text { Moderately } \\
\text { severe }\end{array}$ & Severe & $\begin{array}{l}\text { Most } \\
\text { severe }\end{array}$ & Total \\
\hline Highly & 24.6 & 14.49 & 17.55 & 4.65 & 61.3 \\
\hline \multicolumn{6}{|l|}{ Vulnerable } \\
\hline Vulnerable & 6.25 & 2.26 & 3.59 & 0.66 & 12.77 \\
\hline Not & 12.37 & 8.38 & 4.52 & 0.66 & 25.93 \\
\hline \multicolumn{6}{|l|}{ vulnerable } \\
\hline Total & 43.22 & 25.13 & 25.66 & 5.98 & 100 \\
\hline
\end{tabular}

Source: Data Analysis

Table 11: VFII and CPI for post-harvest households

\begin{tabular}{|c|c|c|c|c|c|}
\hline \multirow[b]{2}{*}{ VFII groups } & \multicolumn{5}{|c|}{ CPI for post-harvest households (\%) } \\
\hline & $\begin{array}{l}\text { Least } \\
\text { severe }\end{array}$ & $\begin{array}{l}\text { Moderately } \\
\text { severe }\end{array}$ & Severe & $\begin{array}{l}\text { Most } \\
\text { severe }\end{array}$ & Total \\
\hline Highly & 16.95 & 13.04 & 21.51 & 10.82 & 62.32 \\
\hline \multicolumn{6}{|l|}{ Vulnerable } \\
\hline Vulnerable & 4.17 & 2.61 & 3.52 & 1.83 & 12.13 \\
\hline Not & 8.34 & 5.87 & 8.74 & 2.61 & 25.55 \\
\hline \multicolumn{6}{|l|}{ vulnerable } \\
\hline Total & 29.47 & 21.51 & 33.77 & 15.25 & 100 \\
\hline
\end{tabular}

Source: Data Analysis 


\subsection{Ranking of states in South-South Region of Nigeria by VFII, PCC, CPI and FCS}

Table 12 shows the ranking of 6 states in South-South Nigeria by VFII, PCC, CPI, and FCS. Except for the CPI which ranks by descending order, other indicators use ascending order to rank states (see Table 2 for their threshold). We compared the output of two states -Edo and Bayelsa because they represent two extremes of vulnerability -least vulnerable (Edo) and highly vulnerable (Bayelsa) state.

In Edo state which had the least vulnerability to food insecurity, households tend to have consumed sufficient calories, and they rank second in per capita calorie consumption. On average, post-planting households uses least coping strategy as they ranked second, while post-harvest households use mildly severe coping strategy as they ranked fourth. Their food consumption score was the highest and ranked first, meaning that, compared to other states, Edo state households consumed highly diversify food.

Comparing Edo states with Bayelsa state, households in Bayelsa state are classified as highly vulnerable to food insecurity by VFII. They had the worst level of vulnerability to food insecurity. Their per capita calorie consumption was the worst; they ranked sixth. Both post planting and post-harvest households used a severe coping strategy; they ranked fifth. The food consumption score was ranked fourth meaning that on average household's dietary diversity consumption in this state was borderline. From this discussion, we showed that VFII is a valuable tool for policy making and its ranking are reliable because the VFII incorporates vulnerability dimension in addition to other dimension of food security. Also, the VFII is consistent with other single indicators of food security but goes beyond what other indicators capture. 
Table 12: Ranking of State by VFII and other traditional indicators

\begin{tabular}{llllll}
\hline States & VFII ranking & PCC ranking & $\begin{array}{l}\text { CPI_PH } \\
\text { ranking }\end{array}$ & $\begin{array}{l}\text { CPI_PP } \\
\text { ranking }\end{array}$ & FCS ranking \\
\hline Edo & 1 & 2 & 4 & 2 & 1 \\
Cross River & 2 & 1 & 6 & 6 & 6 \\
Delta & 3 & 3 & 1 & 1 & 5 \\
Rivers & 4 & 5 & 2 & 3 & 2 \\
Akwa Ibom & 5 & 4 & 3 & 4 & 3 \\
Bayelsa & 6 & 6 & 5 & 5 & 4 \\
\hline
\end{tabular}

Source: Data Analysis

\section{Conclusion}

In this paper, we have shown how we designed an indicator that addresses the problem of vulnerability to food insecurity and comparing it to other traditional indicators of food security. We have also shown how single indicators can be misrepresentative regarding vulnerability to food insecurity. Because traditional food security indicators measure different food security phenomena. Therefore, in other to successfully target intervention to vulnerable household, the VFII can get the right measurement. Thus, ensuring that the exclusion error is drastically reduced and scare resource are adequately targeted to the needed groups of vulnerable households. For example, in Table 9, there are two significant insight from this table. The first insight is that out of $74.63 \%$ of households who had poor per capita calorie consumption, $19.13 \%$ of households were not vulnerable to food insecurity although they had deficient calorie consumption. Secondly, a more significant proportion of households, $17.88 \%$ out of $25.37 \%$, had consumed above the recommended per capita calorie consumption yet they were either highly vulnerable or mildly vulnerable to food insecurity. The implication of this is that using per capita calorie consumption alone to capture food vulnerability will provide a misleading result because of the exclusion and inclusion error. The evidence from this paper shows that using per capita calorie consumption alone for longterm targeting of intervention would include $19.13 \%$ of households that should not have been included. Similarly, $17.88 \%$ of households will be excluded, that should have been included in long-term intervention when using per capita calorie consumption. Another insight form VFII is that using households' current dietary diversity alone is not a consistent indicator of 
vulnerability to food insecurity. Table 8 shows out of $86.78 \%, 63.02 \%$ of households had consumed food with acceptable levels of dietary diversity yet these households were either vulnerable or highly vulnerable to food insecurity.

The overall takeaway point from using single indicators is that they represent different food security phenomena and they do not take in to account multidimensional issues of food security like food vulnerability. The evidence presented in this paper justify the need for a robust model like our vulnerability to food insecurity index. We showed in section 5.3 that VFII being a multidimensional index can capture food vulnerability and other single food indicators like current calories consumption, dietary diversity and coping strategy. For longterm food security intervention, policymakers need to target households based on their vulnerability and not their current consumption or dietary diversity. In conclusion, to accurately target long-term support to vulnerable households, policymakers who seek to address the underlying causes of food insecurity cannot rely on single indicators, and for this type of goal, the VFII makes a useful contribution.Advancing a multidimensional index like VFII requires better surveys and more panel data to increase a more precise assessment of food insecurity especially in developing countries.

\section{References}

Abson, D. J., Dougill, A. J. \& Stringer, L. C. (2012). Using principal component analysis for information-rich socio-ecological vulnerability mapping in Southern Africa. Applied Geography, 35, 515-524.

Adepoju, A. O., Yusuf, S. A., Omonona, B. T. \& Okunmadewa, F. Y. (2011). Vulnerability profile of rural households in South West Nigeria. Journal of Agricultural Science, 3, 128-139.

Adger, W. N. (2006). Vulnerability. Global Environmental Change, 16, 268-281.

Antwi-Agyei, P., Fraser, E. D., Dougill, A. J., Stringer, L. C. \& Simelton, E. (2012). Mapping the vulnerability of crop production to drought in Ghana using rainfall, yield, and socioeconomic data. Applied Geography, 32, 324-334.

Barrett, C. B. (2010). Measuring food insecurity. Science, 327, 825-828.

Bashir, M. K. \& Schilizzi, S. (2012). Measuring food security: Definitional sensitivity and implications. 56th Australian Agricultural \& Resource Economics Society annual conference. Western Australia.

Berkes, F. \& Folke, C. (1998). Linking social and ecological systems for resilience and sustainability. In: Berkes, F. \& Folke, C. (eds.) Linking social and ecological systems. Cambridge: Cambridge University Press.

Bickel, G., Nord, M., Price, C., Hamilton, W. \& Cook, J. (2000). Guide to measuring household food security. US Department of Agriculture, Food and Nutrition Service, Alexandria VA, 1-82.

Brooks, N., Adger, W. N. \& Kelly, P. M. (2005). The determinants of vulnerability and adaptive capacity at the national level and the implications for adaptation. Global environmental change, 15, 151-163. 
Capaldo, J., Karfakis, P., Knowles, M. \& Smulders, M. (2010). A model of vulnerability to food insecurity. ESA working paper (No. 10-03), FAO: Rome.

Cardona, O. D., van Aalst, M. K., Birkmamm, J., Fordham, M., McGregor, G., Perez, R., Pulwarty, R. S., Schipper, E. L. F. \& Sinh, B. T. (2012). Determinants of risk: exposure and vulnerability. In: Field, C. B., Barros, V., Stocker, T. F., Qin, D., Dokken, D. J., Ebi, K. L., Mastrandread, M. D., Mach, K. J., Plattner, G. K., Allen, S. K., Tignor, M. \& Midgley, P. M. (eds.) Managing the risks of extreme events and disasters to advance climate change adaptation. Cambridge, UK, and New York, USA: A Special Report of Working Groups I and II of the Intergovernmental Panel on Climate Change (IPPC).

Chaudhuri, S., Jalan, J. \& Suryahadi, A. (2002). Assessing households vulnerability to poverty from cross-sectional data: A methodology and estimates from Indonesia. New York: Columbia University.

Christiaensen, L. J. \& Boisvert, R. N. (2000). On measuring household food vulnerability: Case evidence from Northern Mali. Ithaca, NY: Department of Agricultural, Resource, and Managerial Economics, Cornell University.

Corral, P., Molini, V. \& Oseni, G. (2015). No condition is permanent: Middle class in Nigeria in the last decade. Policy research working paper 7214 . World Bank Group.

Dary, O. \& Imhoff-Kunsch, B. (2010). Guide to estimating per capita consumption of staple foods using Household Income and Expenditure Survey (HIES) data. ECSA/A2Z Monitoring and Evaluation Workshop. Uganda.

de Sherbinin, A. (2014). Spatial climate change vulnerability assessments: A review of data, methods, and issues. USA: United States Agency for International Development.

de Sherbinin, A., Chai-Onn, T., Giannini, A., Jaiteh, M., Levy, M., Mara, V., Pistoles, L. \& Trzaska, S. (2014). Mali climate vulnerability mapping. USA: United State Agency for International Development.

Deitchler, M., Ballard, T., Swindale, A. \& Coates, J. (2011). Introducing a simple measure of household hunger for cross-cultural use. Food and Nutrition Technical Assistance 2: Technical Note 12. Washington DC: USAID.

Dotter, C. \& Klasen, S. (2014). The Multidimensional Poverty Index: Achievements, Conceptual, and Empirical Issues. Occasional Paper. New York: UNDP Human Development Report Office.

Elbers, C. \& Gunning, J. W. (2003). Vulnerability in a Stochastic Dynamic Model. Ttinergen Institute Discusion Paper $T 1$ 2003-07/2. Amsterdam: Tinbergen Institute.

Engle, N. L. (2011). Adaptive capacity and its assessment. Global Environmental Change, 21, 647656.

FAO (1968). Food composition table for use in Africa. In: Leung, W.-T. W., Busson, F. \& Jardin, C. (eds.). Maryland, USA: US Department of Health, Education, and Welfare.

FAO (1996). World food summit-Rome declaration on world food security and WFS plan of action. Rome: WFS document. FAO.

FAO, INFOODS, WAHO \& BIODIVERSITY-INTERNATIONAL (2012). West African Food Composition Table. Rome: Food and Agriculture Organization of the United Nations.

FAO \& WHO (1996). Study on the impact of armed conflicts on the nutritional situation of children. Rome: Food and Agricultural Organization.

Fellmann, T. (Year). The assessment of climate change-related vulnerability in the agricultural sector: reviewing conceptual frameworks. In: Building resilience for adaptation to climate change in the agriculture sector. Proceedings of a Joint FAO/OECD Workshop, Rome, Italy, 23-24 April 2012., 2012. Food and Agriculture Organization of the United Nations (FAO), 37-61.

Freudenberg, M. (2003). Composite indicators of country performance: A critical assessment. Paris: OECD.

Fry, K., Firestone, R. \& Chakraborty, N. M. (2014). Measuring equity with national representative wealth quintiles. Washington, DC: PSI.

Gbetibouo, G. A., Ringler, C. \& Hassan, R. (2010). Vulnerability of the South African farming sector to climate change and variability: An indicator approach. Natural Resources Forum, 34, 175187.

Günther, I. \& Harttgen, K. (2009). Estimating households vulnerability to idiosyncratic and covariate shocks: A novel method applied in Madagascar. World Development, 37, 1222-1234.

Hahn, M. B., Riederer, A. M. \& Foster, S. O. (2009). The Livelihood Vulnerability Index: A pragmatic approach to assessing risks from climate variability and change-A case study in Mozambique. Global Environmental Change, 19, 74-88. 
Hinkel, J. (2011). "Indicators of vulnerability and adaptive capacity": Towards a clarification of the science-policy interface. Global Environmental Change, 21, 198-208.

Hoddinott, J. \& Quisumbing, A. (2003). Data sources for microeconometric risk and vulnerability assessments. Social Protection Discussion Paper Series NO. 0323. Washington D.C: World Bank.

Hoddinott, J. \& Quisumbing, A. (2008). Methods for microeconometric risk and vulnerability assessments. Washington D.C: International Food Policy Research Institute.

Hoogeveen, J., Tesliuc, E., Vakis, R. \& Dercon, S. (2004). A guide to the analysis of risk, vulnerability and vulnerable groups. World Bank. Washington, DC. Available online at http://siteresources. world bank. org/INTSRM/Publications/20316319/RVA. pdf. Processed.

IPPC (2001). Climate change 2001: Impacts, Adaptation, and Vulnerability. Contribution of Working Group II to the Third Assessment Report of the Intergovernmental Panel on Climate Change. In: McCarthy, J. J., Canziani, O. F., Leary, N. A., Dokken, D. J. \& White, K. S. (eds.). Cambridge, UK and New York, USA: Cambridge University Press.

IPPC (2007). Climate change 2007: Impacts, Adaptation and Vulnerability. Contribution of Working Group II to the Third Assessment Report of the Intergovernmental Panel on Climate Change. In: Parry, M. L., Canziani, O. F., Palutikof, J. P., Van der Linder, P. J. \& Hanson, C. E. (eds.). Cambridge, UK: Cambridge University Press.

Jones, A. D., Ngure, F. M., Pelto, G. \& Young, S. L. (2013a). What Are We Assessing When We Measure Food Security? A Compendium and Review of Current Metrics. Advances in Nutrition, 4, 481-505.

Jones, A. D., Ngure, F. M., Pelto, G. \& Young, S. L. (2013b). What Are We Assessing When We Measure Food Security? A Compendium and Review of Current Metrics. Advances in Nutrition, 4, 481-505.

Karfakis, P., Knowles, M., Smulders, M. \& Capaldo, J. (2011). Effect of global warming on vulnerability in rural Nicaragua. ESA working paper No. 11-18. Rome: FAO.

Klennert, K. (ed.) (2005). Achieving food and nutrition security: Actions to meet the global challenge - A training course reader. Germany: Internationale Weiterbildung und Entwicklung gGmbH.

Krishnamurthy, P., Lewis, K. \& Choularton, R. (2014). A methodological framework for rapidly assessing the impacts of climate risk on national-level food security through a vulnerability index. Global Environmental Change, 25, 121-132.

Lovendal, C. R. \& Knowles, M. (2005). Tomorrow's hunger: A framework for analyzing vulnerability to food insecurity. Rome: FAO.

LSHTM (2009). The use of epidemiological tools in conflict-affected populations: open-access educational resources for policy-makers. Calculation of z-scores. London: London School of Hygiene and Tropical Medicine.

Lucas, P. \& Hilderink, H. (2005). Vulnerability Concept and its Application to Food Security. RIVM rapport 550015004.

Madu, I. A. (2012). Spatial vulnerability of rural households to climate change in Nigeria: Implication for internal security. Working Paper No. 2. Texas: Robert S. Strauss centre for international security and law.

Malcomb, D. W., Weaver, E. A. \& Krakowka, A. R. (2014). Vulnerability modelling for sub-Saharan Africa: An operationalized approach in Malawi. Applied Geography, 48, 17-30.

Maxwell, D. \& Caldwell, R. (2008). The coping strategies index: field methods manual. 2 ed. Atlanta, GA: CARE.

Maxwell, D., Coates, J. \& Vaitla, B. (2013). How do different indicators of household food security compare? Empirical evidence from Tigray. Medford:USA: Feinstein International Center, Tufts University.

Maxwell, D., Vaitla, B. \& Coates, J. (2014). How do indicators of household food insecurity measure up? An empirical comparison from Ethiopia. Food policy, 47, 107-116.

McCarthy, J. J., Canziani, O. F., Leary, N. A., Dokken, D. J. \& White, K. S. (eds.) (2001). Impacts, Adaptation, and Vulnerability. Cambridge: Cambridge University Press.

Moss, R. H., Brenkert, A. L. \& Malone, E. L. (2001). Vulnerability to climate change: A quantitative approach. USA: United State Department of Energy.

NBS (2015). Basic Information Document: Nigeria General Household Survey - Panel 2010/2011. Nigeria: National Bureau of Statistics.

NBS \& LSMS (2015). Basic Information Document: Nigeria General Household Survey - Panel 2012/13. Nigeria: National Bureau of Statistics. 
O'Brien, K., Eriksen, S., Nygaard, L. P. \& Schjolden, A. (2007). Why different interpretations of vulnerability matter in climate change discourses. Climate policy, 7, 73-88.

OECD (2008). Handbook on Constructing Composite Indicators: Methodology and User Guide. Italy: Joint Research Center, European Commission.

Polsky, C., Neff, R. \& Yarnal, B. (2007). Building comparable global change vulnerability assessments: The vulnerability scoping diagram. Global Environmental Change, 17, 472-485.

Ruststein, S. O. \& Johnson, K. (2004). The DHS Wealth Index. Calverton, Maryland: ORC Macro.

Saltelli, A. (2017). Sensitivity Analysis. Bergen: Centre for the study of Sciences and HumanitiesUniversity of Bergen.

Scaramozzino, P. (2006). Measuring vulnerability to food security. Rome: ESA working paper (No. 06-12).

Singh, C. (2014). Understanding water scarcity and climate variability: an exploration of farmer vulnerability and response strategies in northwest India. Unpublished doctoral dissertation, University of Reading.

Smith, L. C. \& Subandoro, A. (2007). Measuring Food Security using household expenditure survey. Washington D.C: International Food Policy Research Institute.

Sobol', I. y. M. (1967). On the distribution of points in a cube and the approximate evaluation of integrals. USSR Computational Mathematics and Mathematical Physics, 7, 784-802.

UNDP (2007). Human Development Report 2007/2008: Fighting climate change: Human Solidarity in a divided world. New York, USA: United Nation Development Programme.

Vaitla, B., Coates, J., Glaeser, L., Hillbruner, C., Biswal, P. \& Maxwell, D. (2017). The measurement of household food security: Correlation and latent variable analysis of alternative indicators in a large multi-country dataset. Food Policy, 68, 193-205.

Villagrán de León, J. C. (2006). Vulnerability. A Conceptual and Methodological Review.

Webb, P. \& Bhatia, R. (2005). Manual: Measuring and Interpreting Malnutrition and Mortality. Nutr Serv WFP Rome.

WHO (2011). WHO child growth standards: WHO Anthro (version 3.2.2) and macros. Rome: World Health Organization.

Woller, G., Wolfe, J., Brand, M., Parrot, L., Fowler, B., Thompson, J., Dempsey, J., Berkowitz, L. \& van Haeften, B. (2013). Livelihood and food security conceptual framework. Livelihood and Food Security Technical Assistance. Washington, DC: FHI 360.

World-Bank \& NBS (2014). Nigeria General Household Survey -Panel 2012/2013. In: World-Bank $\&$ National-Bureau-of-Statistics (eds.) Wave 1 ed. Nigeria.

World-Bank \& NBS (2015). Nigeria General Household Survey -Panel 2010/2011. In: World-Bank \& National-Bureau-of-Statistics (eds.) Wave 2 ed. Nigeria.

Young, H. \& Jaspars, S. (2006). The meaning and measurement of acute malnutrition in emergencies: A primer for decision-makers. London, UK: Overseas development institute (ODI). Humanitarian practice network (HPN).

\section{Appendix A: Procedures for deriving some variables of VFII}

\section{How malnutrition variables were derived and computed}

Anthropometric information is widely and commonly used to determine an individual nutritional status. Statistically, it is expressed using either the standard deviations from the median (commonly called the z-scores) or percentage of the median (Webb and Bhatia, 2005; LSHTM, 2009). This study uses the z-scores to express the anthropometrics information of children from $0-60$ months in the study. To do this, data such as weight of child( $\mathrm{kg})$, height of child (cm), age (in months) and gender from the panel survey were used. Using WHO child growth standard macro (WHO, 2011) which is design to calculates z-scores statistics 
for four anthropometry indices such as weight-for-age (underweight), length/height-for-age (stunting), weight-for-length/height (wasting), and BMI-for-age. The macro (igrowup_resricted.ado) in combination with five permanent WHO child growth standards read-only stata data sets, estimates the prevalence of under/over nutrition and summary statistics (mean and standard deviation) of the z-scores for each anthropometrics. Only the zscores for the stunting was retained and used for further analysis. Table A shows these $\mathrm{z}-$ scores values are to classify households.

Table A: Cut-off point of malnutrition for underweight, stunting, and wasting based on zscores.

\begin{tabular}{|l|l|}
\hline Classification & Z-score values \\
\hline Adequate & $-2<$ Z-score $<+2$ \\
\hline Moderately malnourished & $-3<$ Z-score $<-2$ \\
\hline Severely malnourished & Z-score $<-3$ \\
\hline
\end{tabular}

Sources: Webb and Bhatia (2005)

How hunger indicator was derived and calculated:

To calculate hunger, the HHS uses three core questions and three frequencies to estimates the percentage of households in a population that are affected by hunger as shown in Table $\mathrm{B}$ (Deitchler et al., 2011). Categorizing the hunger result into three different severities - (1) little to no household hunger (2) moderate household hunger; and (3) severe household hunger. However, this research is limiting its interest only to get the values and not categorising the values. These values are now used to represent the hunger indicator for the sensitivity dimension of the vulnerability to food insecurity index. 
Table B: Shows in brief the HHS core questions and frequencies

\begin{tabular}{|l|l|l|}
\hline S/N & Core questions (Scale items) & $\begin{array}{l}\text { Frequency categories (Response } \\
\text { codes) }\end{array}$ \\
\hline 1 & No food to eat of any kind in your household & Never, Rarely or Sometimes, Often \\
\hline 2 & Go to sleep at night hungry & Never, Rarely or Sometimes, Often \\
\hline 3 & Go a whole day and night without eating & Never, Rarely or Sometimes, Often \\
\hline & Recall Period: 4 weeks \\
\hline
\end{tabular}

Source: Adapted from (Deitchler et al., 2011)

Based on the frequency selected on each core question, a total score is gotten, which is the HHS score. This score ranges from 0 (minimum) to 6 (being the maximum). It is derived by summing the response codes which are never $=0$, rarely or sometimes $=1$ and often $=2$. So, the total HHS score is now used to categorise levels of severity of hunger. The lower the score, the lesser the experience of hunger in the household but the higher the score the severe hunger level in households. Using this concept, this research computed the hunger score for households in the study with a moderate change because the frequency category was missing from the dataset used in this research. Instead of using the three questions design for HHS, the research used only question 2 and 3 (Table B). The reason is that these two questions represent the extremities of hunger which captures the hidden hunger and micronutrient deficiencies. Also, the minimum recommended recall period to be used in the HHS is four weeks or 30 days but, in the household, dataset it was seven days only. Since there was no frequency category, using only two core questions instead of three questions and using seven days' recall period, the maximum HHS score is 14 , and the minimum is 0 . For example, a household was asked out of 7 days in a week how many days do you: (a) go to sleep at night hungry (b) go a whole day and night without eating. The answer was 4, and 5 days respectively. Thus, the HHS score will be $4+5=9$. This method was repeated for all household to generate the hunger score. According to (Deitchler et al., 2011), the pitfall with using a shorter recall period like seven days over the recommended four weeks (30 days) period is that this may not capture the full extent of hunger deprivation experience since fluctuation in food accessibility is common within 1-month recall.

Caveat: There are two subsets of household panel data in a wave, these are: post planting and post harvesting. Both have food security data and specifically the data needed to be used for calculating hunger. It will be good to compare hunger changes between the two periods, but 
since the VFII is not design for either season but a wave or year, the research made use of hunger data from the post-harvesting period only.

\section{Procedures used in designing wealth index:}

1. Sorting of variables: variables were commonly grouped into three categories: agricultural (livestock, land, crops); assets (livelihood asset, mobility asset, information asset) and housing structure characteristics. The following steps were used to prepare these variables for analysis:

a. In sorting out variables needed for the wealth index, some were dropped, and others merge.

b. Created dichotomous variable - this help to regroup variables.

c. Variables with zero variance were remove

d. Finally, replace variables with missing observation with zeros

2. Standardization of variables: Each variable used in the wealth index calculation was standardised so that they are all on the same scale and can be compared.

a. The standardised score was calculated using this: standardise score $=($ variable - mean)/standard deviation

3. Factor weight: To calculate the factor weight, Principal Component Analysis (PCA) was run, and the first principal component (eigenvectors) was retained. These values were then used to multiply by the standardise scores to get the factor weight. Thus, factor weight $=$ standardize $*$ first principal components (eigenvectors).

4. Computing the wealth index: summing all factor weight of each variable for each household produces the wealth index scores.

5. Categorizing wealth index scores: The wealth index scores were categorized into five quintiles, with the lowest score being the poorest and the highest score being the wealthiest.

\section{How livelihood activities are derived}

There are three significant livelihood sources identified in the LSMS household survey data. The data gotten from these sources are combined to produce a measure of livelihood activities in the research. They are discussed in detail below: 
- Income sources: - These are total income from savings, rental of property and any other type of income. The following computation is used to generate "income sources": Total income household received from savings interest or investment since the new year plus Total amount household usually receive from the rental of property (excluding agricultural land) within the new year plus Total regular income of any other type. The data used for "income sources" come from post planting data because it is the primary source of information compared to the post-harvest data that which has only additional income available after the post-planting visit.

- Non-farm enterprises operated by households: Non-farm enterprise is defined as any member of the household who worked for him/herself other than on a farm or raising animals. Such enterprise includes personal business, trade, self-employed professional or craftsman. The computation used to generate this variable is to calculate revenue made from non-farm enterprises: Total sales - Total cost of the business (includes the following cost: salaries and wages, purchase of goods for sale, transport, insurance, rent, interest, raw materials and others).

- Agricultural activities: These are livelihood activities derived from crop farm. The data is generated by collating the total yield of crop harvested per year in kilograms for each farming household. 


\section{Table C: Detailed description of indicators and variables of VFII}

\begin{tabular}{|c|c|c|}
\hline $\begin{array}{l}\text { Index } \\
\text { components }\end{array}$ & Indicators & Variables description and rationale \\
\hline \multirow{5}{*}{$\begin{array}{l}\text { Exposure } \\
\text { probability of } \\
\text { covariate shocks } \\
\text { occurring }\end{array}$} & Health shock & $\begin{array}{l}\text { From the household dataset "illness of income earning member" was selected and used } \\
\text { as Health Shock in the Vulnerability to Food Insecurity Index. }\end{array}$ \\
\hline & $\begin{array}{l}\text { Unemployment } \\
\text { shock }\end{array}$ & $\begin{array}{l}\text { "Job loss" is used as a variable to represent unemployment shock in the Vulnerability to } \\
\text { Food Insecurity Index. Job loss reduces the ability of households to buy food, get clean } \\
\text { water and medicines because of loss of income, therefore increasing household food } \\
\text { insecurity and vulnerability (FAO and WHO, 1996). }\end{array}$ \\
\hline & $\begin{array}{l}\text { Civil conflict } \\
\text { shocks }\end{array}$ & $\begin{array}{l}\text { From the household survey data, the variable used to represent Civil conflict shock are: } \\
\text { "Theft of crops, cash and livestock" and "kidnapping/Hijacking/robbery/assault". }\end{array}$ \\
\hline & $\begin{array}{l}\text { Agro-climatic } \\
\text { shocks }\end{array}$ & $\begin{array}{l}\text { Agro-climatic shocks have the potential for increasing food insecurity and malnutrition. } \\
\text { Based on the household's survey data the variables used for agro-climatic shocks are: } \\
\text { "poor rain that caused harvest failure" and "flooding that caused harvest failure. }\end{array}$ \\
\hline & Food price shock & $\begin{array}{l}\text { From the household survey data, the variable used to represent food price shock is } \\
\text { "increase in price of major food items consumed". }\end{array}$ \\
\hline \multirow{3}{*}{$\begin{array}{l}\text { Sensitivity } \\
\text { previous or } \\
\text { accumulative } \\
\text { experience of } \\
\text { food insecurity }\end{array}$} & Malnutrition & $\begin{array}{l}\text { Malnutrition is the most widely accepted and policy relevance variable commonly used } \\
\text { are wasted, stunted, and underweight (Klennert, 2005). However, this research prefers to } \\
\text { use stunting as an indicator of malnutrition. Stunting was preferred because it shows } \\
\text { inadequate nutrition over a prolonged period (Young and Jaspars, 2006). }\end{array}$ \\
\hline & Child mortality & $\begin{array}{l}\text { Child mortality, defined as the total number of dead children in each household was } \\
\text { derived by adding "number of male children" and/or "female children" reported dead in } \\
\text { each household. }\end{array}$ \\
\hline & Hunger & $\begin{array}{l}\text { This research refers hunger to the physical discomfort caused by a lack of food (Bickel } \\
\text { et al., 2000; Barrett, 2010) and not as a result of dieting or being too busy to eat. As such } \\
\text { it represents hidden hunger, that is micronutrient deficiencies (Jones et al., 2013a). Thus, } \\
\text { hunger is a severe stage of food insecurity. To derive this indicator, the research adopts } \\
\text { the Household Hunger Scale (HHS) methodology with a little modification due to } \\
\text { inadequate data availability. }\end{array}$ \\
\hline \multirow[t]{2}{*}{$\begin{array}{l}\text { Adaptive } \\
\text { Capacity } \\
\text { how household } \\
\text { respond, exploit } \\
\text { opportunities, } \\
\text { resist or recover } \\
\text { from food } \\
\text { insecurity shocks }\end{array}$} & Wealth Index & $\begin{array}{l}\text { The wealth index is a measure of economic status of households to ascertain their } \\
\text { relative wealth (Ruststein and Johnson, 2004; Fry et al., 2014). The wealth index used in } \\
\text { this research uses various household asset such as information assets, mobility assets, } \\
\text { livelihood assets, and housing characteristics to design the index. The following } \\
\text { variable were used in designing the wealth index: Livelihood assets: Tables, mattress, } \\
\text { bed, mat, fridge, freezer, sofa set, chair, sewing machine, kerosene stove, other assets, } \\
\text { generator, size of agricultural land, broiler chicken, cockerel, local chicken, goat, pig, } \\
\text { duck and sheep. Mobility assets: Bicycle, motorbike, cars and other vehicles. } \\
\text { Information asset: Radio, TV set, computer, satellite dish, DVD player, GSM mobile } \\
\text { phone/landline, cassette recorder. Housing structure characteristics: Outer wall, roof } \\
\text { materials, floor material, members per room, lighting fuel, cooking fuel, access to } \\
\text { electricity, main source of drinking water during dry season, main source of drinking } \\
\text { water during the wet season, type of toilet facilities, type of user who shared toilet } \\
\text { facilities, and refuse disposal facilities. }\end{array}$ \\
\hline & $\begin{array}{l}\text { Access } \\
\text { infrastructure }\end{array}$ & $\begin{array}{l}\text { This research uses distance to major roads, distance to markets and time taken to get to } \\
\text { nearest water source to represent a single indicator called "assess to infrastructure". }\end{array}$ \\
\hline
\end{tabular}




\begin{tabular}{|l|l|l|}
\hline \multirow{2}{*}{$\begin{array}{l}\text { Livelihood } \\
\text { activities }\end{array}$} & $\begin{array}{l}\text { Income sources, revenue from non-farm enterprises and agricultural activities are used } \\
\text { as variable to represent livelihood activities. These are three major sources of livelihood } \\
\text { identified in the LSMS household survey data. }\end{array}$ \\
\cline { 2 - 4 } & $\begin{array}{l}\text { Cumulative years of schooling of household head or closet individual is one of the main } \\
\text { criteria used in defining household literacy. Years of schooling are used as a proxy for } \\
\text { literacy and level of understanding of household members, including household heads. } \\
\text { An individual is considered literate if he or she has at least five years of education } \\
\text { (Dotter and Klasen, 2014). Only post-planting season data were used to derive this } \\
\text { indicator because it contains information on household head needed to represent literacy } \\
\text { level of the household. In rare cases where there was no data on the household head, the } \\
\text { closest individual in educational achievement that has at least five years of schooling is } \\
\text { used as a replacement for household head. If educational qualifications are the same for } \\
\text { more than one individual, the most senior individual in age is used. }\end{array}$ \\
\hline
\end{tabular}

\section{Food energy conversion table}

Table D: Food Composition Table for Food Items used in Nigeria (100 Grams Edible portion)

\begin{tabular}{|l|l|l|l|l|}
\hline $\begin{array}{l}\text { Item } \\
\text { code }\end{array}$ & Food item & $\begin{array}{l}\text { Food energy } \\
\text { (kilocalories) }^{\mathrm{A}}\end{array}$ & $\begin{array}{l}\text { Food } \\
{\text { (calories })^{\mathrm{B}}}^{\text {(n)ergy }}\end{array}$ & Edible Portion \\
\hline 10 & Guinea corn/sorghum & 344 & 350 & 1.00 \\
\hline 11 & Millet & 348 & 349 & 1.00 \\
\hline 12 & Maize & 349 & 357 & 1.00 \\
\hline 13 & Rice - local & 349 & 344 & 1.00 \\
\hline 14 & Rice - imported & 352 & 353 & 1.00 \\
\hline 15 & Bread & 249 & 261 & 1.00 \\
\hline 16 & Maize flour & 354 & 365 & 1.00 \\
\hline 17 & Yam flour & 312 & 335 & 1.00 \\
\hline 18 & Cassava flour & 335 & & 1.00 \\
\hline 19 & Wheat flour & 351 & 364 & 1.00 \\
\hline 20 & Other grains and flour & & 345 & 1.00 \\
\hline 30 & Cassava - roots & 347 & 357 & 1.00 \\
\hline 31 & Yam - roots & 141 & 112 & 0.81 \\
\hline 32 & Gari - white & & 351 & \\
\hline 33 & Gari - yellow & & 351 & 1.00 \\
\hline 34 & Cocoyam & 136 & 102 & 0.65 \\
\hline 35 & Plantains & 140 & 135 & 1.00 \\
\hline 36 & Sweet potatoes & 115 & 121 & 1.00 \\
\hline 37 & Potatoes & 80 & 82 & 1.00 \\
\hline 38 & Other roots and tuber & 137 & & 1.00 \\
\hline 40 & Soya beans & 410 & 405 & 1.00 \\
\hline 41 & Brown beans & 318 & 342 & 1.00 \\
\hline 42 & White beans & 335 & 338 & \\
\hline 43 & Groundnuts & 578 & 549 & \\
\hline & & & & \\
\hline
\end{tabular}




\begin{tabular}{|c|c|c|c|c|}
\hline 44 & Other nuts/seeds/pulses & 593 & & 0.37 \\
\hline 50 & Palm oil & 900 & & 1.00 \\
\hline 51 & Butter/Margarine & 730 & & 1.00 \\
\hline 52 & Groundnut oil & 900 & & 1.00 \\
\hline 53 & Other oils and fats & 900 & & 1.00 \\
\hline 60 & Bananas & 106 & 88 & 0.64 \\
\hline 61 & Orange/tangerine & 45 & & 0.73 \\
\hline 62 & Mangoes & 76 & & 0.71 \\
\hline 63 & Avocado pear & 154 & & 0.74 \\
\hline 64 & Pineapples & 54 & & 0.51 \\
\hline 65 & Fruit canned & N/A & N/A & N/A \\
\hline 66 & Other fruits & N/A & N/A & N/A \\
\hline 70 & Tomatoes & 22 & & 0.91 \\
\hline 71 & Tomato puree (canned) & 20 & & 1.00 \\
\hline 72 & Onions & 33 & & 0.91 \\
\hline 73 & Garden eggs/egg plant & 30 & & 0.81 \\
\hline 74 & Okra - fresh & 33 & & 0.86 \\
\hline 75 & Okra - dried & N/A & N/A & N/A \\
\hline 76 & Pepper & 45 & & 0.73 \\
\hline 77 & $\begin{array}{l}\text { Leaves (cocoyam, spinach, } \\
\text { etc.) }\end{array}$ & 42 & & 0.80 \\
\hline 78 & $\begin{array}{l}\text { Other vegetables (fresh or } \\
\text { canned) }\end{array}$ & 42 & & 0.80 \\
\hline 80 & Chicken & 218 & & 0.66 \\
\hline 81 & Duck & N/A & N/A & N/A \\
\hline 82 & Other domestic poultry & 232 & & 0.65 \\
\hline 83 & Agricultural eggs & 139 & & 0.88 \\
\hline 84 & Local eggs & 139 & & 0.88 \\
\hline 85 & Other eggs (not chicken) & 139 & & 0.88 \\
\hline 90 & Beef & 126 & & 1.00 \\
\hline 91 & Mutton & 257 & & 0.82 \\
\hline 92 & Pork & 265 & & 1.00 \\
\hline 93 & Goat & 165 & & 0.74 \\
\hline 94 & Wild game meat & N/A & N/A & N/A \\
\hline 95 & Canned beef/corned beef & 243 & & 1.00 \\
\hline 96 & Other meat (excl. poultry) & 127 & & 0.76 \\
\hline 100 & Fish - fresh & 124 & & 0.71 \\
\hline 101 & Fish - frozen & 124 & & 0.71 \\
\hline 102 & Fish - smoked & 151 & & 0.64 \\
\hline 103 & Fish - dried & 151 & & 0.64 \\
\hline 104 & Snails & N/A & N/A & N/A \\
\hline 105 & $\begin{array}{l}\text { Seafood (lobster, crab, } \\
\text { prawns, etc.) }\end{array}$ & 119 & & 0.54 \\
\hline 106 & Canned fish/seafood & 220 & & 1.00 \\
\hline 107 & Other fish or seafood & 126 & & 0.55 \\
\hline 110 & Fresh milk & 65 & & 1.00 \\
\hline 111 & Milk powder & 495 & & 1.00 \\
\hline 112 & Baby milk powder & 519 & & 1.00 \\
\hline
\end{tabular}




\begin{tabular}{|c|c|c|c|}
\hline 113 & Milk tinned (unsweetened) & 135 & 1.00 \\
\hline 114 & Other milk products & 73 & 1.00 \\
\hline 120 & Coffee & 354 & 1.00 \\
\hline 121 & $\begin{array}{l}\text { Chocolate drinks (including } \\
\text { Milo) }\end{array}$ & 386 & 1.00 \\
\hline 122 & Tea & 0 & 1.00 \\
\hline 130 & Sugar & 400 & 1.00 \\
\hline 131 & Jams & Dropped & \\
\hline 132 & Honey & 326 & 1.00 \\
\hline 133 & $\begin{array}{ll}\begin{array}{l}\text { Other sweets and } \\
\text { confectionary }\end{array} & \end{array}$ & Dropped & \\
\hline 140 & $\begin{array}{lll}\begin{array}{l}\text { Condiments } \\
\text { pepper, etc) }\end{array} & \text { (salt, spices, } \\
\end{array}$ & 348 & 1.00 \\
\hline 150 & Bottled water & Dropped & \\
\hline 151 & Sachet water & Dropped & \\
\hline 152 & Malt drinks & Dropped & \\
\hline 153 & Soft drinks & Dropped & \\
\hline 154 & Fruit juice canned/Pack & 44 & 1.00 \\
\hline 155 & Other non-alcoholic drinks & Dropped & \\
\hline 160 & Beer (local and imported) & 35 & 1.00 \\
\hline 161 & Palm wine & 34 & 1.00 \\
\hline 162 & Pinto & Dropped & \\
\hline 163 & Gin & Dropped & \\
\hline 164 & Other alcoholic beverages & Dropped & \\
\hline
\end{tabular}

Source: FAO et al. (2012) and FAO (1968) 
Table E: Household Adult Equivalent

\begin{tabular}{|c|c|c|c|c|c|}
\hline \multicolumn{4}{|c|}{ Males } & \multicolumn{2}{|l|}{ Female } \\
\hline \multicolumn{2}{|c|}{$\begin{array}{l}\text { Age } \\
\text { (years) }\end{array}$} & $\begin{array}{l}\text { Energy } \\
\text { (Kcal/day) }\end{array}$ & Ad. Eq. & $\begin{array}{l}\text { Energy } \\
\text { (Kcal/day) }\end{array}$ & Ad. Eq \\
\hline \multicolumn{2}{|c|}{$<1$} & 661 & 0.22 & 661 & 0.22 \\
\hline 1 & 2 & 950 & 0.31 & 850 & 0.28 \\
\hline 2 & 3 & 1125 & 0.37 & 1050 & 0.34 \\
\hline 3 & 4 & 1250 & 0.41 & 1150 & 0.38 \\
\hline 4 & 5 & 1350 & 0.44 & 1250 & 0.41 \\
\hline 5 & 6 & 1475 & 0.48 & 1325 & 0.43 \\
\hline 6 & 7 & 1575 & 0.52 & 1425 & 0.47 \\
\hline 7 & 8 & 1700 & 0.56 & 1550 & 0.51 \\
\hline 8 & 9 & 1825 & 0.60 & 1700 & 0.56 \\
\hline 9 & 10 & 1975 & 0.65 & 1850 & 0.61 \\
\hline 10 & 11 & 2150 & 0.70 & 2000 & 0.66 \\
\hline 11 & 12 & 2350 & 0.77 & 2150 & 0.70 \\
\hline 12 & 13 & 2550 & 0.84 & 2275 & 0.75 \\
\hline 13 & 14 & 2775 & 0.91 & 2375 & 0.78 \\
\hline 14 & 15 & 3000 & 0.98 & 2450 & 0.80 \\
\hline 15 & 16 & 3175 & 1.04 & 2500 & 0.82 \\
\hline 16 & 17 & 3325 & 1.09 & 2500 & 0.82 \\
\hline 17 & 18 & 3400 & 1.11 & 2500 & 0.82 \\
\hline 18 & 30 & 3050 & 1.00 & 2400 & 0.79 \\
\hline 30 & 60 & 2950 & 0.97 & 2350 & 0.77 \\
\hline \multicolumn{2}{|c|}{$>=60$} & 2450 & 0.80 & 2100 & 0.69 \\
\hline
\end{tabular}

Source: Dary and Imhoff-Kunsch (2010) 


\title{
Appendix B: Uncertainty and Sensitivity Analysis: Robustness check for Vulnerability to Food Insecurity Index
}

\begin{abstract}
This paper systematically evaluates the effect of some methodological or assumptions on the robustness of Vulnerability to Food Insecurity Index. The focus was to examine how data type, weight scheme, normalisation method and exclusion/inclusion of variable affect the model of the index using uncertainty and sensitivity analysis. The paper used two approaches: One-at-a-time and global sensitivity approach for the analysis. Using one-at-atime approach, we explore how the VFII output response to different weighting scheme, normalisation method and inclusion/exclusion of variable. For the global approach, we used Sobol' first-order index and total effect index to explore the uncertainty and sensitivity of VFII. The result of the robustness analysis indicated that VFII performance is stable to changes in the variables and normalisation method when equal weight is applied. Using the min-max normalisation method produces a highly robust estimate. The shock variable was the primary input factor that influences the variation in the output of the VFII. This implies that the VFII is highly sensitive to shocks, therefore better capturing the vulnerability component of food security.
\end{abstract}

Keywords: Food security, vulnerability, food vulnerability index, sensitivity, robustness, first-order, total-effect

\subsection{Introduction}

Several assumptions have been used to construct the Vulnerability to Food Insecurity Index (VFII). Notably assumptions in the selection of indicators, the normalisation of indicators, the weighting of the indicators, the aggregation method used, and categorising the index. These assumptions can have a significant impact on the output and reliability of the Vulnerability to Food Insecurity Index. Therefore, sensitivity and uncertainty analysis are needed to establish the robustness of the methodology and the assumptions made in the construction of the VFII (Esty et al., 2006). We will also use sensitivity and uncertainty analysis to test if a useful conclusion can be made from Vulnerability to Food Insecurity Index. The sensitivity analysis will numerically quantify how variation or uncertainty in the 
VFII output can be apportioned to diverse sources in model input while the uncertainty analysis will focus on quantifying the uncertainty in the VFII output only (Saltelli, 2017). The accuracy and precision of the VFII depend on the following factors: the computational method for estimating missing data, the mechanism for inclusion and exclusion of variables, the transformation of variables when constructing the index, type of normalisation method, amount of missing data, weighting scheme adopted, the level and choice of aggregation method used. Using uncertainty and sensitivity analysis this research will systematically evaluate the effect of some of the above methodological processes on the robustness of the Vulnerability to Food Insecurity Index scoring and ranking. The following questions will be investigated:

1. How does the output of the VFII rank compare to different assumptions?

2. What is the major source of uncertainty in the VFII ranking?

3. What are the most influential input factors that cause this uncertainty in VFII ranking?

We use two main approaches to conduct uncertainty and sensitivity analysis namely: One-atat-time (OAT) and global sensitivity analysis approach. Using one-at-time approach, we change one assumption or factor at a time and then compare the output. We use OAT to carry out only uncertainty analysis for some assumptions because it was the most suitable method to used base on our model. Although the uncertainty analysis using the OAT approach is criticised as being non-conservative (Saltelli,2007). Global sensitivity approach is widely preferred in literature because it explores the entire effect of each factor or assumptions on the model output and numerically quantifies the effect of different source of uncertainty in the model input (Saltelli et al., 2004).

This paper is organised into sections. The next section (section 2) presents a thorough discussion on the research methodology applied. Section three discusses the result/insight from findings and section four present the conclusion.

\subsection{Methodology}

\subsection{Structure of Vulnerability to Food Insecurity Index}

The VFII is a mathematical model derived from contextual vulnerability concept. The contextual approach, view's household vulnerability as a multidisciplinary system consisting of the biophysical and socio-economic environment (Fellmann, 2012). These two-system interaction influences household food vulnerability. Using the vulnerability lens to unpack 
the meaning and operationalise vulnerability measurement regarding food security. We discovered that vulnerability has three main components (Cardona et al., 2012; IPPC, 2007). These components are the exposure, sensitivity and adaptive capacity. In this paper, we define exposure as those food-related shocks that affect households access to safe and nutritious food. Using the theme derived from conceptual vulnerability, that household vulnerability is affected by its socio-economic and biophysical condition; we selected indicators and variables for the exposure component (Fellmann, 2012; Adger, 2006). The sensitivity component of our VFII represents the previous or accumulative experience of food insecurity within the household such as stunting, child mortality and hunger (Hahn et al., 2009a). Household ability to successfully adjust to the effect of food shocks using the livelihoods assets means that they have strong adaptive capacity (Woller et al., 2013). Households with a strong and more liquid livelihood asset will be less vulnerable to food insecurity. We used this conceptual underpinning to select the indicators and variable for the VFII, shown in Figure 1. A summary of indicators and variables are presented in Table 1.

\section{Figure 1: Vulnerability to Food Insecurity Index components and indicators}

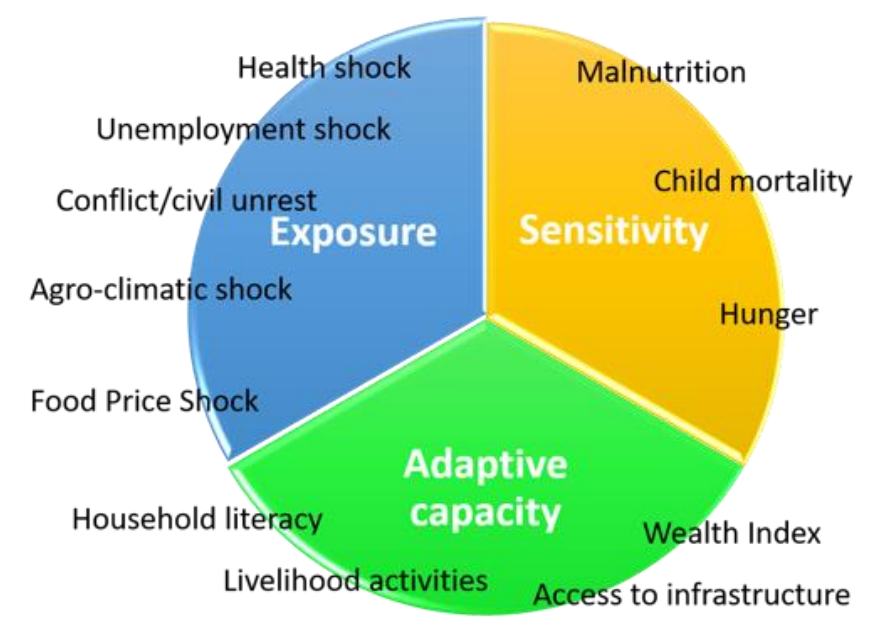

Source: Developed by the author 
Table 1: Indicators and variables used for the Vulnerability to Food Insecurity Index

\begin{tabular}{|c|c|c|}
\hline Index Dimension & Indicators & Description of variables \\
\hline \multirow{6}{*}{$\begin{array}{c}\text { Exposure } \\
\text { (probability of } \\
\text { covariate shocks } \\
\text { occurring) }\end{array}$} & Health shock & Illness of income earning member \\
\hline & Unemployment shock & Job loss \\
\hline & \multirow[t]{2}{*}{ Civil conflict shock } & Theft of crops, cash, livestock or other \\
\hline & & Kidnapping/Hijacking/robbery/assault \\
\hline & \multirow[t]{2}{*}{ Agro-climatic shock } & Poor rain that caused harvest failure \\
\hline & & Flooding that caused harvest failure \\
\hline & Food price shock & Increase in price of major food items consumed \\
\hline \multirow{3}{*}{$\begin{array}{c}\text { Sensitivity } \\
\text { (Previous/accumulative } \\
\text { experience of food } \\
\text { insecurity) }\end{array}$} & Malnutrition & Length/height-for-age (stunting) \\
\hline & Child mortality & Total number of children dead in each household \\
\hline & Hunger & $\begin{array}{l}\text { Total number of days' households gone without eating } \\
\text { any food. }\end{array}$ \\
\hline \multirow{11}{*}{$\begin{array}{l}\text { Adaptive Capacity } \\
\text { how household } \\
\text { respond, exploit } \\
\text { opportunities, resist or } \\
\text { recover from food } \\
\text { insecurity shocks }\end{array}$} & \multirow[t]{4}{*}{ Wealth Index } & Household assets used to assess information \\
\hline & & Mobility assets used in households \\
\hline & & Livelihood assets own by households \\
\hline & & Housing structure characteristics \\
\hline & \multirow[t]{3}{*}{ Access to infrastructure } & Household distance to nearest major road $(\mathrm{km})$. \\
\hline & & Household distance to nearest market (km). \\
\hline & & $\begin{array}{l}\text { Time taken to walk one way to the water source from } \\
\text { household dwelling (minutes). }\end{array}$ \\
\hline & \multirow[t]{3}{*}{ Livelihood activities } & $\begin{array}{l}\text { Total income from savings, rental of properties and } \\
\text { other types of income. }\end{array}$ \\
\hline & & Estimated revenue from non-farm enterprises \\
\hline & & Total yield of crops harvested (kg) \\
\hline & Household literacy & $\begin{array}{l}\text { Cumulative years of schooling for household heads or } \\
\text { closest individual in the household. }\end{array}$ \\
\hline
\end{tabular}

Note: The Closest individual is the next individual in the household if education is missing for the household head, who has the highest level of education, and at least five years of schooling. If educational qualifications are the same for more than one individual, the most senior individual in age is used.

\subsubsection{Construction of the VFII}

We developed a conceptual framework and selected indicators for the index (see Figure 1). Then we generated weight, either PCA or equal weight for variables and then each component of VFII; normalised these variables using either min-max or z-score method (see equation 3 and 4) and used the aggregation formula in equation (1) to generate the index scores (OECD, 2008). 


$$
V F I I_{i}=\sum A C_{i}-\left(\sum E_{i}+\sum S_{i}\right)
$$

Where $V F I I_{i}$ is the score for Vulnerability to Food Insecurity Index for $i$ household, $A C_{i}$ is adaptive capacity, $E_{i}$ is exposure and $S_{i}$ is sensitivity. The $V F I I_{i}$ score are then used to rank and categorize household vulnerability to food security. The higher the value of VFII composite score, the less households are vulnerable to food insecurity and vice versa.

\subsection{Data Source}

The dataset used for this research is the General Household Survey Panel (GHS-Panel), which is a Living Standard Measurement Study (LSMS) survey from the World Bank. The dataset contains a panel component (GHS-Panel) which is a randomly selected sub-sample of 5,000 households from a cross-sectional survey of 22,000 households carried out annually throughout the country. The dataset contains information on human capital, economic activities, access to services and resources, food security and additional information on agricultural activities and household's consumption is collected from the panel households. The GHS-Panel has two waves: the first wave (2010-2011) and second wave (2012-2013). In each wave, visits are carried out within two periods to panel households. The first period is the post-planting visit in August-October 2010 (wave 1) while September - November 2012 (for wave 2) and the second period is the post-harvest visit in February-April 2011 \& 2013 for both waves respectively. A onetime visit is carried out for the cross-section along with the post-harvest visit to the panel households (NBS, 2015; NBS and LSMS, 2015; World-Bank and NBS, 2015; World-Bank and NBS, 2014; Corral et al., 2015).

\subsection{Normalization and Weighting Method}

The normalisation method used in the construction of Vulnerability to Food Insecurity Index (VFII) variables are based on the Min-Max (equation 3) or standardise (equation 4) value method. Consider the VFII value of selected states in Nigeria $c, c=1, \ldots . M$,

$$
\begin{gathered}
V F I I_{c}=f_{r s}\left(I_{1, c}, I_{2, c}, \ldots I_{Q, c}, w_{s, 1}, w_{s, 2}, \ldots . w_{s, Q}\right), \ldots \ldots \\
\text { where }\left\{\begin{array}{l}
I_{q, c}=\frac{x_{q, c}-\min \left(x_{q}\right)}{\operatorname{range}\left(x_{q}\right)} \ldots \ldots \ldots \ldots \ldots \\
I_{q, c}=\frac{x_{q, c}-\operatorname{mean}\left(x_{q}\right)}{\operatorname{std}\left(x_{q}\right)} \ldots \ldots \ldots \ldots .
\end{array}\right.
\end{gathered}
$$


The weighing method $f_{r s}$, where the index $r$ refer to the linear aggregation scheme used, and index $s$ refers to the weighting scheme (PCA weight and equal weights). The index is based on $Q$ normalised individual indicators $I_{1, c}, I_{2, c}, \ldots I_{Q, c}$ for states in Nigeria and schemedependent weights $w_{s, 1}, w_{s, 2,}, \ldots . w_{s, Q}$ for the individual indicators. $I_{Q, c}$ is the normalised and $x_{q, c}$ is the raw value of the individual indicator $x_{q}$ for states in Nigeria.

\subsection{Uncertainty and sensitivity analysis model}

We used two approaches to carry out our uncertainty and sensitivity analysis, namely one-ata-time and global sensitivity approach. The methods adopted from these approaches are explained in this section.

\subsubsection{One-at-a-time-approach}

This approach tests the effect of a single input or factor on the output one at a time. We used this method to test the performance of the VFII on different weighting method, normalisation method and excluding/including a variable. We applied two types of data in this approach for comparison purpose and to test the robustness of our VFII. Using dataset with missing or incomplete observations and data set that had complete observation. To get a complete data, we used multiple imputation method, running a multiple regression with observable household characteristics variables to impute those variables that had missing data.

\subsubsection{Uncertainty analysis}

To know the primary source of variability in the ranking of states by the VFII, we carried out an uncertainty analysis. This focus on quantifying uncertainty in the model output (Saltelli et al., 2008). We investigated the difference between the output $\left(V F I I_{B E}\right)$ of two states (Bayelsa and Edo state) composite score as shown in the equation 5.

$$
V F I I_{B E}=\left(V F I I_{\text {Edo state }}-V F I I_{\text {Bayelsa state }}\right)
$$

In the first step, we must ascertain the presence of uncertainty in the input factors used to produce the output in equation 2 and equation 5. Our main area interest will be on the following assumptions that can introduce uncertainty in our output variables:
a. The selection of variables
b. The normalisation method
c. The weighting schemes
d. Exclusion and inclusion of variable(s) 
The input factors defined as everything that causes a variation or uncertainty in the output of the model (Saltelli et al., 2008), is presented in Table 2. These are 12 weighted variables with their probability distribution function (PDF). Also included are additional three trigger variables to represent the type of normalisation (either min-max or z-score), weighting scheme (equal or unequal (PCA) weight) and exclusion or inclusion of variable (either child mortality or distance-to-water-source).

We use the Global approach to perform the uncertainty analysis (Saltelli, 2017). Using Monte Carlo analysis, which is based on using the probabilistic value of the model input to estimate multiple model evaluations and then using these evaluations to determine (1) the uncertainty in the model prediction and (2) the input factors that caused the uncertainty. We followed the following procedures as laid out by (Saltelli et al., 2004; Saltelli et al., 2008):

I. Determine the probability distribution function (mean and standard deviation see table in Appendix VI) of each input factor parameters. $X_{1}, X_{2}$, and $X_{3}$ are triggers to select the weighting method, normalization method and variables excluded or included.

II. From each of these input factors, we produce a set of row vectors in such a that the vectors are sampled from the PDF of input factor parameter.

III. Then we compute the model for all vectors, thereby producing a set of $\mathrm{N}$ values for the model output in equation 1 and 5.

IV. From these, we can now compute the average output, standard deviation, quartiles distribution, confidence bounds and plot these distributions.

V. To compute the number of simulation for a model with k factors, only $N(k+2)$ model runs were needed. Where $k$ is the total number of input factors and $N=1024$ is quasi-random sample scheme (Sobol', 1967). 
Table 2: Uncertainty input factor probability distribution function

\begin{tabular}{|c|c|c|c|}
\hline Input factor & Description & PDF & Range \\
\hline $\mathrm{SH}$ & Weighted shock & Normal & - \\
\hline $\mathrm{CM}$ & Weighted child mortality & Normal & - \\
\hline ST & Weighted stunting & Normal & - \\
\hline $\mathrm{HU}$ & Weighted hunger & Normal & - \\
\hline WI & Weighted wealth index & Normal & - \\
\hline DR & Weighted distance-to-road & Normal & - \\
\hline $\mathrm{DM}$ & Weighted distance-to-market & Normal & - \\
\hline DW & Weighted distance-to-water & Normal & - \\
\hline IS & Weighted income-savings & Normal & - \\
\hline NI & Weighted non-farm-income & Normal & - \\
\hline CY & Weighted crop yield & Normal & - \\
\hline HL & Weighted household literacy & Normal & - \\
\hline $\mathrm{X}_{1}$ & $\begin{array}{l}\text { Weighting method (either } \\
\text { equal weight or unequal } \\
\text { (PCA) weight }\end{array}$ & Discrete & $\begin{array}{l}{[0,1] \text { where }[0,0.5]} \\
=\text { equal weights and } \\
(0.5,1]=\text { PCA weight }\end{array}$ \\
\hline $\mathrm{X}_{2}$ & $\begin{array}{l}\text { Normalization method (min- } \\
\text { max or z-score values) }\end{array}$ & Discrete & $\begin{array}{l}{[0,1] \text { where }[0,0.5]} \\
=\min -\max \text { and } \\
(0.5,1]=\text { z-score }\end{array}$ \\
\hline $\mathrm{X}_{3}$ & $\begin{array}{l}\text { Inclusion-Exclusion (either } \\
\text { excluding child mortality and } \\
\text { distance-to-water source or } \\
\text { including child mortality and } \\
\text { excluding distance-to-water- } \\
\text { source }\end{array}$ & Discrete & $\begin{array}{l}{[0,1] \text { where }[0,0.5]=} \\
\text { excluding child } \\
\text { mortality and } \\
\text { distance-to-water } \\
\text { source and }(1,0.5]= \\
\text { including child } \\
\text { mortality and } \\
\text { excluding distance- } \\
\text { to-water-source }\end{array}$ \\
\hline
\end{tabular}

\subsubsection{Sensitivity analysis}

We applied the variance-based sensitivity method for our analysis. We are looking at how the overall uncertainty in the input factors affects the output rather than testing one input at a time. Using the variance-based sensitivity method we can decompose the uncertainty in input factors according to their variance and show how output depends on this variance (Saisana et al., 2005; Saltelli et al., 2008). Our primary objective is to look for those factors or groups of factors that when fixed to it true value will reduce the variance of VFII. The reduction in the output variance is highly desirable, and this will mean that the VFII is reliable and robust. We used Sobol' sensitivity indices (Sobol', 1996), which are the first-order and total effect sensitivity indices for our sensitivity analysis. 


\section{First-order sensitivity Index}

The sensitivity index of an input factor $X_{i}$ can be measure by comparing the contribution of it variance to a model output due to uncertainty in $X_{i}$ (Saisana et al., 2005). Looking at the generic model in equation 6.

$$
Y=f\left(X_{1}, X_{2}, \ldots, X_{k}\right)
$$

Each $X$ in equation 6 has a certainty degree of uncertainty or variation, we want to determine what will happen to the uncertainty of $Y$ if we could fix an input factor. Assuming a fixed factor $X_{i}$, at any value be $x_{i}^{*}$. This result to the conditional variance depending on $X_{i}$ which is be fixed to $x_{i}^{*}$. Let $V_{X_{-i}}\left(Y \mid X_{i}=x_{i}^{*}\right)$, which is the resulting variance of $Y$ taken over by all other factors except $X_{i}$. There are two problems to this approach: (1) it is impractical because the sensitivity measure will depend on the position of the point $x_{i}^{*}$ and (2) the conditional variance will be greater than the unconditional variance. Instead of taking sensitivity measure at a fixed point, we rather take average of all possible points $x_{i}^{*}$. Then the dependence on $x_{i}^{*}$ will be remove. Rewriting this as $E_{X_{i}}\left(V_{X_{-i}}\left(Y \mid X_{i}\right)\right)$. This is always lower or equal to output variance $V(Y)$, and

$$
E_{X_{i}}\left(V_{X_{-i}}\left(Y \mid X_{i}\right)\right)+V_{X_{i}}\left(E_{X_{-i}}\left(Y \mid X_{i}\right)\right)=V(Y)
$$

A small $E_{X_{i}}\left(V_{X_{-i}}\left(Y \mid X_{i}\right)\right)$, or a large $V_{X_{i}}\left(E_{X_{-i}}\left(Y \mid X_{i}\right)\right)$, will imply that $X_{i}$ is an important factor. The conditional variance $V_{X_{i}}\left(E_{X_{-i}}\left(Y \mid X_{i}\right)\right)$ is called the first-order effect of $X_{i}$ on $Y$ and the sensitivity measure:

$$
S_{i}=\frac{V_{X_{i}}\left(E_{X_{-i}}\left(Y \mid X_{i}\right)\right)}{V(Y)}
$$

$S_{i}$ is known as the first-order sensitivity index. $S_{i}$ is a number that ranges between 0 and 1 . A higher value denote an important variable. It represent the main effect contribution of each input to the output variance singly (Homma and Saltelli, 1996). When a model first-order term do not add up to one such model is called nonadditive model (i.e. $\sum_{i=1}^{r} S_{i} \leq 1$ ). Alternatively, first-order term add up to one or equal to one, such a model is an additive model (Saltelli et al., 2008).

\section{Total-effect sensitivity index}

First-order sensitivity index measures the effect of individual input on the variance of the output not considering the interaction. Thus, total effect index account for the total 
contribution to the output variation due to factor $X_{i}$. It is the combination of first-order effect and higher-order effect due to interactions.

Total effect can be computed by decomposing unconditional variance into main effect and residual:

$$
V(Y)=V\left(E\left(Y \mid X_{i}\right)\right)+E\left(V\left(Y \mid X_{i}\right)\right)
$$

Alternatively, total effect can be computed by decomposing the output variance into the main effect and residual, conditioning this with time with respect to all factors but one, i.e $X_{\sim i}$ :

$$
V(Y)=V\left(E\left(Y \mid X_{-i}\right)\right)+E\left(V\left(Y \mid X_{-i}\right)\right)
$$

"The measure $V(Y)-V\left(E\left(Y \mid X_{-i}\right)\right)=E\left(V\left(Y \mid X_{-i}\right)\right)$ is remaining variance of $\mathrm{Y}$ that would be left, on average, if $X_{\sim i}$ true values could be determine" (Saltelli et al., 2008). $X_{\sim i}$ are uncertainty input factors and their true values are unknown. To obtain the total effect index for $X_{i}$, we divide by $V(Y)$ :

$$
S_{T_{i}}=\frac{E\left(V\left(Y \mid X_{-i}\right)\right)}{V(Y)}=1-\frac{V\left(E\left(Y \mid X_{-i}\right)\right)}{V(Y)}
$$

Total effect index $\left(S_{T_{i}}\right)$ provide an answer to the question: "which factor can be fixed anywhere over its range of variability without affecting the output?" If $S_{T_{i}}=0$, this means $X_{i}$ has meet the condition of not being an influential factor. If $X_{i} \cong 0$, then $X_{i}$ can be fixed at any range without affecting value of the output variance $V(Y)$ (Tarantola et al., 2007).

\subsection{Result and Discussion}

The primary results presented in this section are guided by the questions raised in section 1.0. This section using the methods described earlier in section 2.0 present the results and the discussion.

3.1 How do the VFII ranks compare under different weighting schemes, the normalisation method, and data types?

This section uses one-at-a-time approach to explore the sensitivity of the index to changes in data type, normalisation method, weighting scheme and exclusion and the inclusion of variable.

\subsubsection{Using unequal weight}

Using principal component analysis, we estimated the weights for each variable used to design the Vulnerability to Food Insecurity Index (VFII) (see Appendix V, for unequal 
weight). PCA gave each component of the index different weight. Weight for exposure, sensitivity and adaptive capacity was $0.0871,-0.5645$ and 1.1322 respectively. Using these weights, we estimated the VFII score for each state using variables with missing data and variable with imputed data. In each scenario, we applied two type of normalisation method (min-max or z-score method). The results are shown in Table 3 and Figure 2. These shows that irrespective of the data type or normalisation method applied, the VFII produces inconsistence ranking of states in South-South region of Nigeria when unequal weight is applied. The level of inconsistencies in ranking was higher when using missing data to estimate the VFII (Table 3). Only Cross River State maintain the same ranking while other states are ranked differently. The implication of using unequal weight means that it does produce a biased estimate of each state performance in terms of food security and vulnerability. This is because of how the VFII component was constructed. The sensitivity and adaptive capacity component have more than one variable compared to the exposure component. Due to data used in designing the index, all the variables in the exposure component were aggregated into one variable, and this made it have a lesser weight compared to another component.

To test the robustness of different VFII specification as shown in Table 4, we computed their pairwise correlation coefficient. Table 4 shows that all the correlation coefficients were significant at 5\% level and most relationships were negatively correlated. Only the combination of VFII with missing data and different normalisation method; and VFII with complete data and different normalisation method had a positive correlation coefficient of 0.85 and 0.69 respectively. With a negative correlation coefficient, we cannot conclude that using PCA weight or unequal with the index can produce a robust estimate. 
Table 3: VFII ranking of states in South-South region of Nigeria using unequal weight and different normalisation methods

\begin{tabular}{lllll}
\hline States & $\begin{array}{l}\text { VFII_missing- } \\
\text { min-max }\end{array}$ & $\begin{array}{l}\text { VFII_missing-z- } \\
\text { score }\end{array}$ & $\begin{array}{l}\text { VFII_complete- } \\
\text { min-max }\end{array}$ & $\begin{array}{l}\text { VFII_complete- } \\
\text { z-score }\end{array}$ \\
\hline Akwa Ibom & 4 & 5 & 4 & 5 \\
Bayelsa & 3 & 1 & 1 & 1 \\
Cross River & 6 & 6 & 3 & 2 \\
Delta & 2 & 2 & 5 & 4 \\
Edo & 5 & 3 & 2 & 3 \\
Rivers & 1 & 4 & 6 & 6 \\
\hline
\end{tabular}

Source: Data Analysis

Figure 2: VFII ranking of States when unequal weight and different normalisation method is used

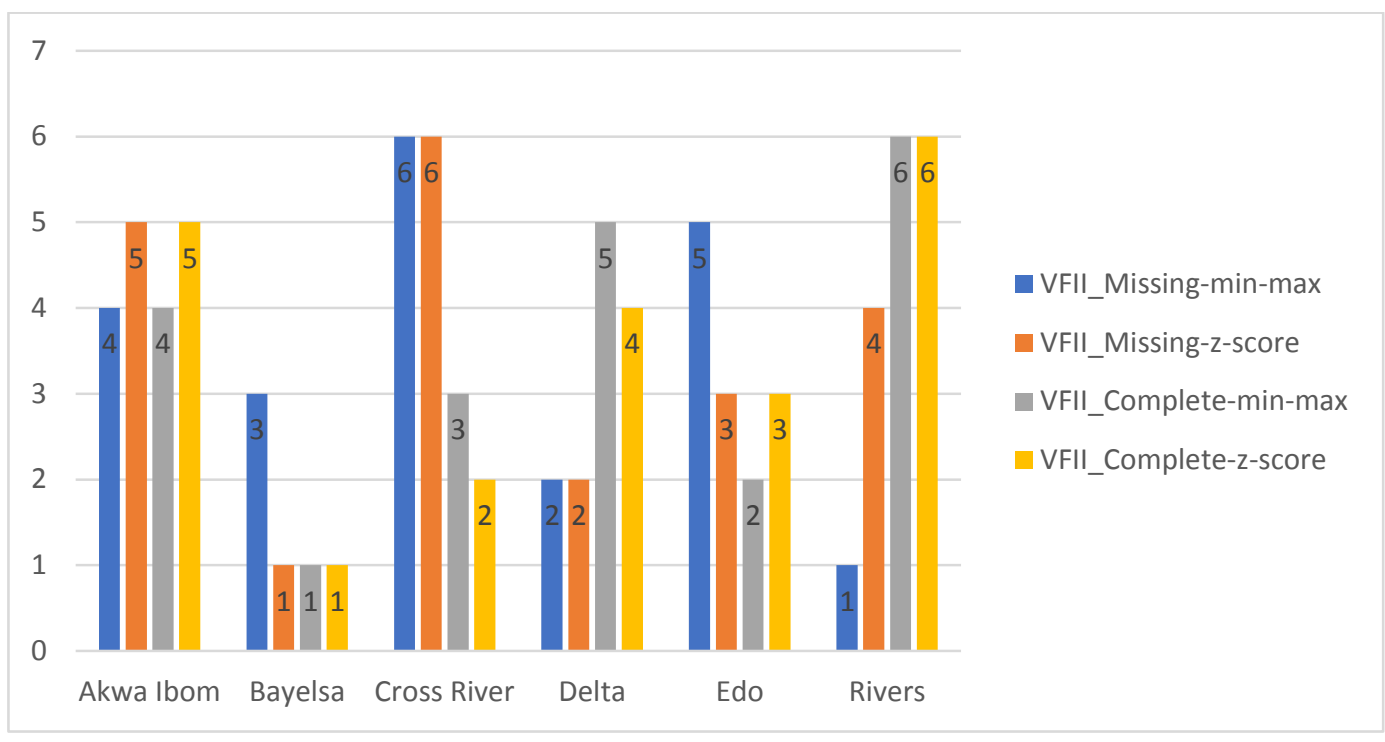

Source: Data Analysis

Table 4: All combinations of VFII pairwise correlation result using unequal weight and different normalisation method

\begin{tabular}{lllll}
\hline $\begin{array}{l}\text { Correlation } \\
\text { Specifications }\end{array}$ & $\begin{array}{l}\text { VFII_missing- } \\
\text { min-max }\end{array}$ & $\begin{array}{l}\text { VFII_missing- } \\
\text { z-score }\end{array}$ & $\begin{array}{l}\text { VFII_complete- } \\
\text { min-max }\end{array}$ & $\begin{array}{l}\text { VFII_complete- } \\
\text { z-score }\end{array}$ \\
\hline $\begin{array}{l}\text { VFII_missing- } \\
\text { min-max }\end{array}$ & 1.00 & & & \\
$\begin{array}{l}\text { VFII_missing- } \\
\text { Z-score }\end{array}$ & $0.85^{* * *}$ & 1.00 & & \\
$\begin{array}{l}\text { VFII_complete- } \\
\text { min-max }\end{array}$ & $-0.70^{* * *}$ & $-0.47^{* * *}$ & 1.00 & \\
$\begin{array}{l}\text { VFII_complete- } \\
\text { Z-score }\end{array}$ & $-0.63^{* * *}$ & $-0.56^{* * *}$ & $0.69^{* * *}$ & 1.00 \\
\hline $\begin{array}{l}\text { Source: Data Analysis } \\
\text { noure }\end{array}$ & & &
\end{tabular}




\subsubsection{Equal weighting}

We decided to apply equal weight to each component of the index to compare its output. Each of the components was given a weight of 0.33 , and these weights were equally shared among the variables in each component (see Appendix IV). Using different data types and normalisation method the result is present in Table 5 and Figure 3. These results show that applying equal weight to the Vulnerability to Food Insecurity Index produce a consistent output and ranking of state, irrespective of the data or normalisation method used. The result supports the notion that using equal weight across the index component produces estimates that are unbiased. According to this result, households in Bayelsa state are highly vulnerable to food insecurity whereas households in Edo state are least or not vulnerable to food insecurity.

To test the robustness of this ranking, we estimated a pairwise correlation coefficient for each specification as shown in Table 6 . Across the table, the correlation coefficient exceeded 0.87 and was highly significant at 5\% level. This suggests that VFII ranking using equal weight are highly robust in its estimate (Alkire and Santos, 2014) unlike using unequal weight as explained in section 3.1.1. Using either min-max or z-score normalisation method for the index will still produce the same output, but the min-max method will produce a better result because it had a correlation coefficient of 0.97 . Based on this finding, we adopted equal weight and min-max normalisation method for our VFII.

Table 5: VFII ranking of states in the South-South region of Nigeria using equal weight and different normalisation methods

\begin{tabular}{lllll}
\hline State & $\begin{array}{l}\text { VFII_missing- } \\
\text { min-max }\end{array}$ & $\begin{array}{l}\text { VFII_missing-z- } \\
\text { score }\end{array}$ & $\begin{array}{l}\text { VFII_complete- } \\
\min -\max \end{array}$ & $\begin{array}{l}\text { VFII_complete- } \\
\text { Z-score }\end{array}$ \\
\hline Akwa Ibom & 5 & 5 & 5 & 5 \\
Bayelsa & 6 & 6 & 6 & 6 \\
Cross River & 2 & 2 & 2 & 2 \\
Delta & 3 & 3 & 3 & 3 \\
Edo & 1 & 1 & 1 & 1 \\
Rivers & 4 & 4 & 4 & 4 \\
\hline
\end{tabular}

Source: Data Analysis 
Figure 3: VFII ranking of States using equal weight and different normalisation method is used

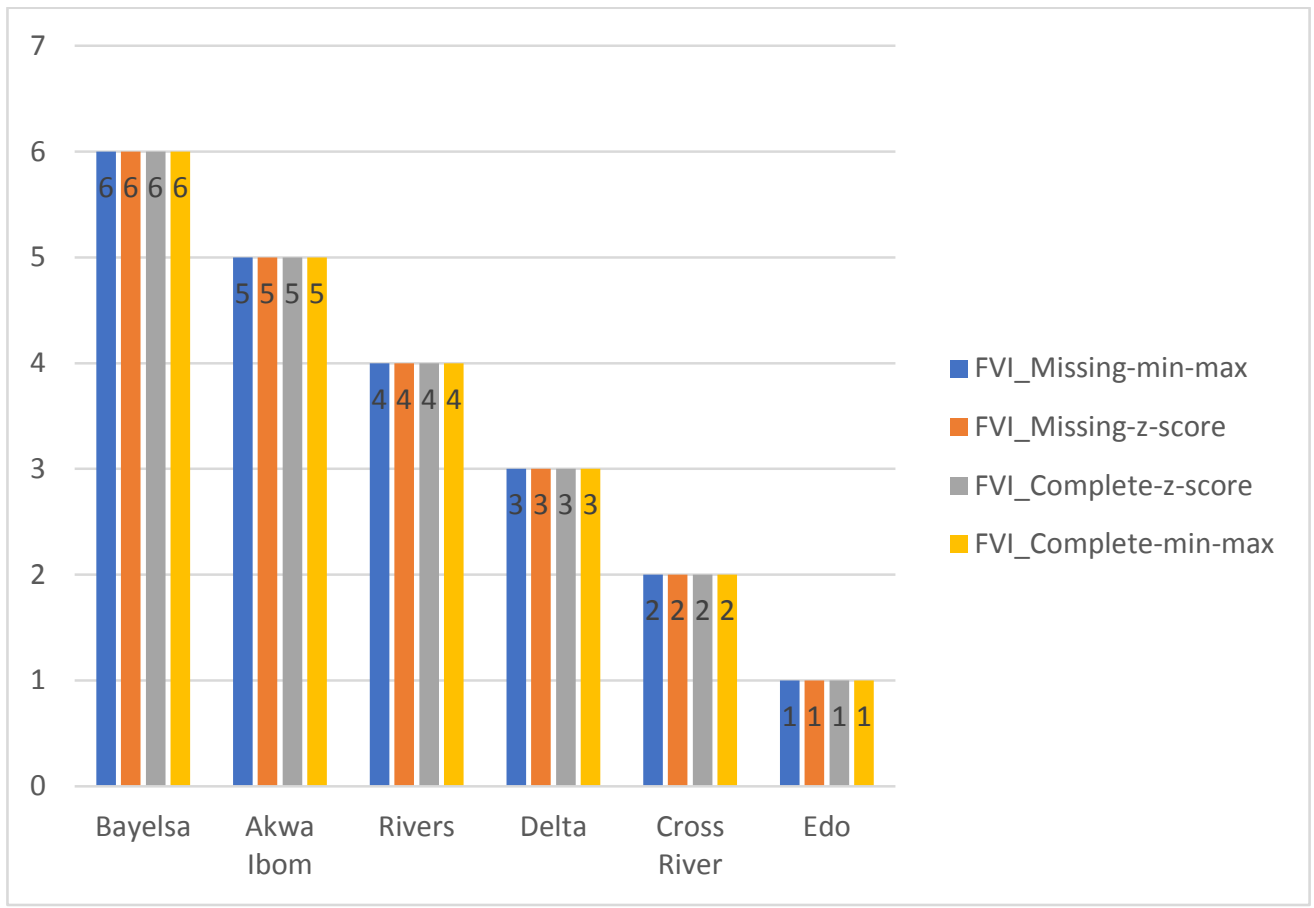

Source: Data Analysis

Table 6: VFII pairwise correlation result applying equal weight to the index

\begin{tabular}{lllll}
\hline & $\begin{array}{l}\text { VFII_missing- } \\
\text { min-max }\end{array}$ & $\begin{array}{l}\text { VFII_missing- } \\
\text { z-score }\end{array}$ & $\begin{array}{l}\text { VFII_complete- } \\
\text { min-max }\end{array}$ & $\begin{array}{l}\text { VFII_complete- } \\
\text { z-score }\end{array}$ \\
\hline $\begin{array}{l}\text { VFII_missing- } \\
\text { min-max }\end{array}$ & 1.00 & & & \\
$\begin{array}{l}\text { VFII_missing- } \\
\text { Z-score }\end{array}$ & $0.87 * * *$ & 1.00 & & \\
$\begin{array}{l}\text { VFII_complete- } \\
\text { min-max }\end{array}$ & $0.97 * * *$ & $0.89 * * *$ & 1.00 & 1.00 \\
$\begin{array}{l}\text { VFII_complete- } \\
\text { Z-score }\end{array}$ & $0.91 * * *$ & $0.93 * * *$ & $0.94 * * *$ & \\
\hline
\end{tabular}

Source: Data Analysis

\subsubsection{Inclusion and Exclusion of variables}

Finally, we went further to test the effect of excluding or including any variable on the index. To determine what variable(s) to be excluded, we estimated the squared multiple correlations of all the variables used in the VFII as shown in Table 7. The squared multiple correlation coefficient shows the interaction of each variable with all other variables. The larger the coefficient, the stronger the interaction of the variable. From Table 7, child mortality and distance-from-water-source were the two variables with the least correlation of $19.71 \%$ and $19.54 \%$. Therefore, we used these variables to carry out the test of either excluding or 
including them. The result of this test is shown in Figure 4 and Table 8. Using equal weight (see appendix for each component weight), Figure 4 and Table 8 shows the robustness of the VFII output. Three specifications were explored: excluding child mortality only; excluding both child mortality and distance-to-water-source; and including child mortality and excluding distance-to-water source. Irrespective of any specification used the VFII ranking was stable across all specification. Comparing the result in Figure 4 and Figure 3, three states -Edo, Cross River, and Delta maintain the same ranking of first, second and third position. Akwa Ibom, Rivers and Bayelsa state ranking differs. For instance, Bayelsa state ranks sixth when using equal weighting method without excluding any variable. Alternatively, when child mortality and distance-to water-source were excluded/included, Bayelsa state ranked third. This slight alteration is expected because of the effect of excluding or including either child mortality or distance-to-water-source on the VFII. However, the overall performance of the VFII remains robust. 
Table 7: Squared multiple correlations of variables with all other variables

\begin{tabular}{cc}
\hline Variable & SMC \\
\hline Shock & 0.3640 \\
Stunting & 0.5032 \\
Hunger & 0.1971 \\
Wealth index & 0.4113 \\
Road distance & 0.5893 \\
Market distance & 0.2663 \\
Distant-to-water-source & 0.3515 \\
Income source & 0.3691 \\
Non-farm Revenue & 0.4725 \\
Crop yield & 0.4248 \\
Household literacy & 0.4836 \\
\hline
\end{tabular}

Source: Data Analysis

Figure 4: VFII ranking when excluding or including variables

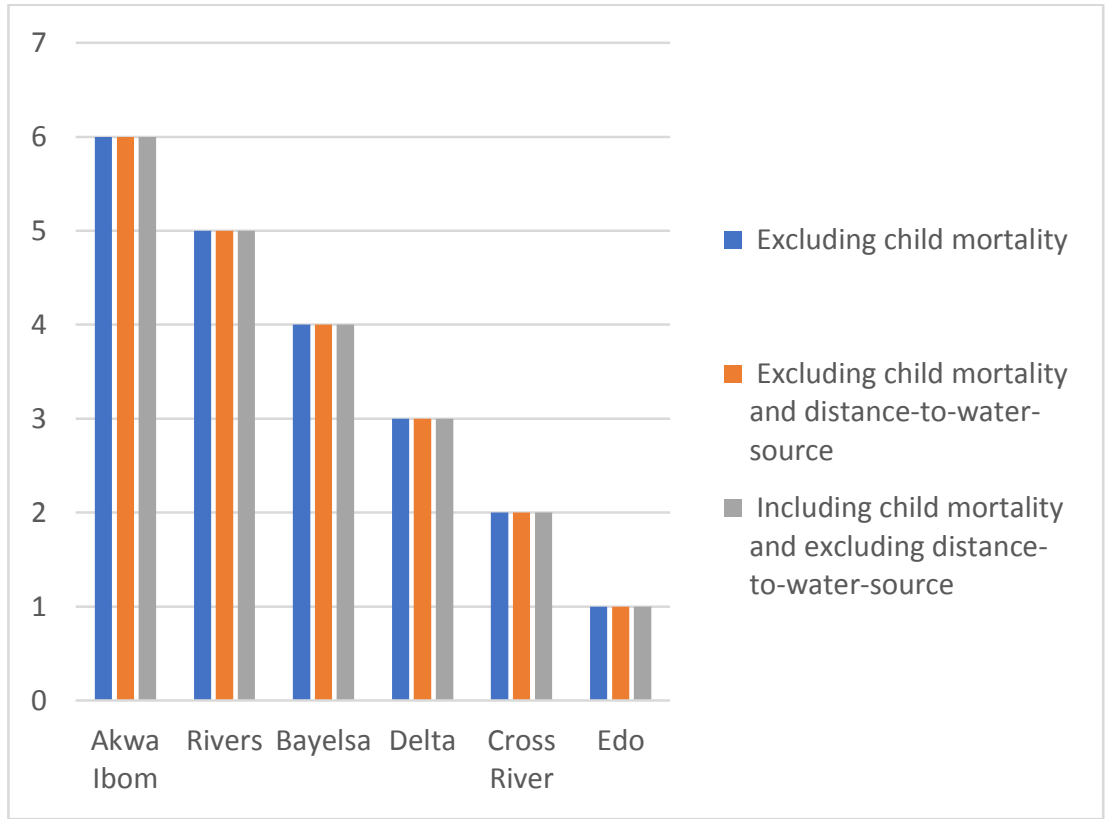

Source: Data Analysis 
Table 8: VFII ranking of state when excluding or including child mortality or distance-towater-source.

\begin{tabular}{lllll}
\hline State & $\begin{array}{l}\text { Excluding } \\
\text { mortality }\end{array}$ & $\begin{array}{l}\text { child } \\
\text { Excluding child Including child mortality } \\
\text { mortality and distance- } \\
\text { to-water-source }\end{array}$ & $\begin{array}{l}\text { and excluding distance to } \\
\text { water source }\end{array}$ \\
\hline Akwa Ibom & 6 & 6 & 6 \\
Bayelsa & 4 & 4 & 4 \\
Cross River & 2 & 2 & 2 \\
Delta & 3 & 3 & 3 \\
Edo & 1 & 1 & 1 \\
Rivers & 5 & 5 & 5 \\
\hline
\end{tabular}

Source: Data Analysis

\subsection{Global Sensitivity Approach}

This section discusses how variation or uncertainty in the output of the VFII can be apportioned to the input factors using global sensitivity analysis as described in section 2.4.2 and section 2.4.3. The area of interest investigated are:

a) What are the major sources of uncertainty in the VFII ranking?

b) What are the most influential input factors that cause this uncertainty in VFII ranking?

The total number of Monte Carlo model execution estimated for the Sobol sensitivity measures - first order and total effect sensitivity indices is 29,696 $(1024 *(27+2))$, where 1024 is sample size adopted by quasi-random scheme (Sobol', 1967), 27 is the total number of input factor used for estimating the model.

3.2.1 Uncertainty Analysis -what are the most influential input factors that cause overlap in two state ranking?

To find out the primary cause of overlap in the VFII ranking, we compare the composite score output of two states - Bayelsa state and Edo state. These two states were selected because Edo is the best-performing state in term of having least food insecurity and vulnerability while Bayelsa state had the highest level of food security and vulnerability. Figure 5 presents the histograms of uncertainty analysis of the differences between the composite scores of these states, which correspond to 29,696 Monte Carlo runs. The lefthand region of Figure 5 shows that Edo state performs better than Bayelsa state in $60 \%$ of the cases. This implies that households in Bayelsa state are more vulnerable to food insecurity 
compare to Edo state. We must find out which uncertainty drive this result. To do this, we estimated the First order $\left(S_{i}\right)$ and Total effect $\left(S_{T i}\right)$ sensitivity indices for Bayelsa and Edo state present in Table 9.

Figure 5: Uncertainty analysis of the difference in composite score between Edo and Bayelsa State. (Uncertainty input factors: 24 weighted indicator values, 3 triggers - weighting, normalisation, inclusion/exclusion)

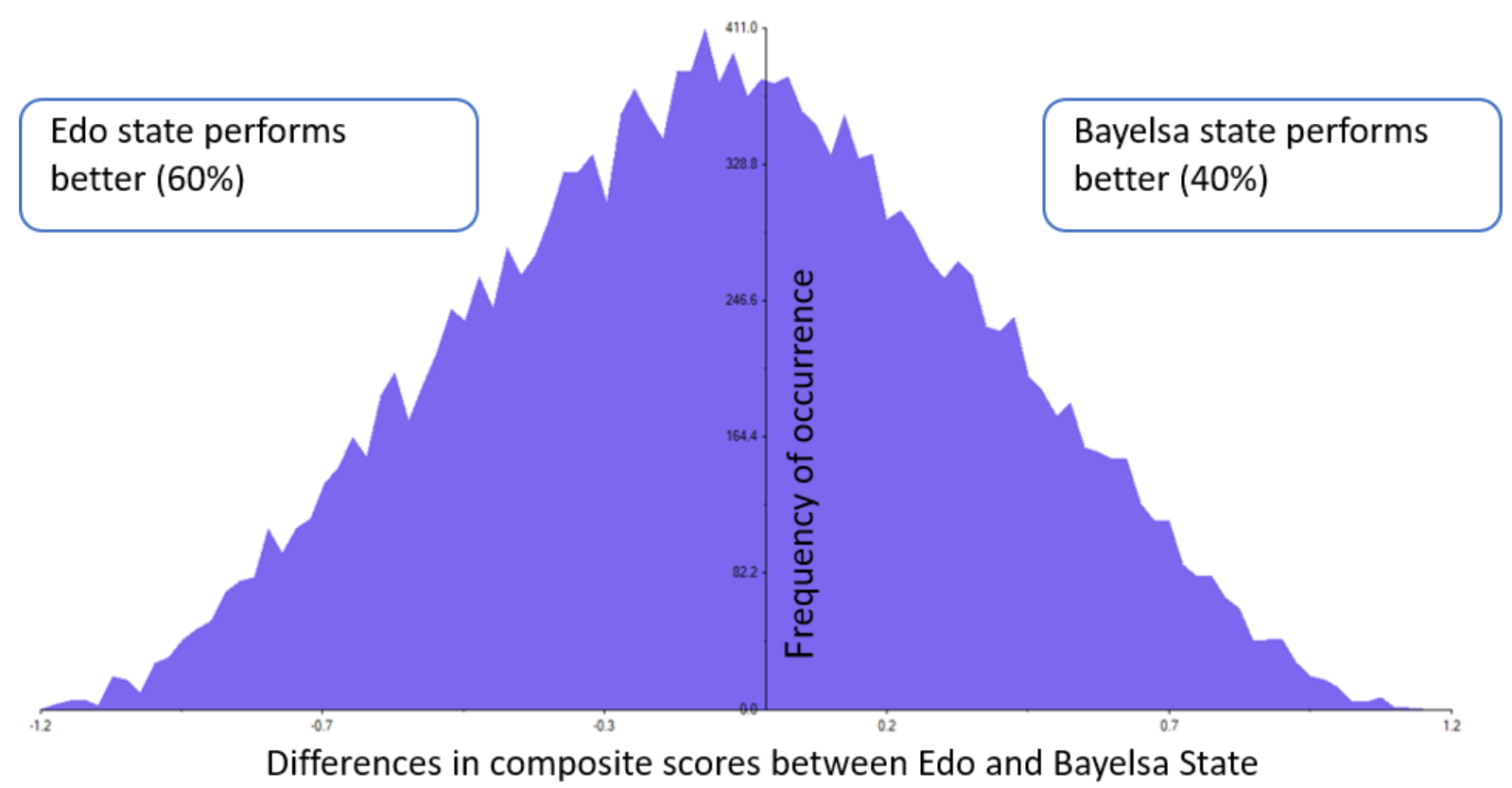

Source: Data Analysis

\subsubsection{Sensitivity Analysis}

When interpreting Sensitivity analysis result, we are looking for important input factors that influence the output. When this input factor is fixed singly, it will reduce the variance of the output significantly. To determine which input factor is important the $S_{i}>0.10$, meaning that the input factor explains more than 1/k of the output variance (Saltelli, 2017).

Table 9 shows the result of the first order sensitivity $S_{i}$. It shows the individual interaction and the main effect between the input factors and the output of Edo and Bayelsa state. Individually, none of the triggers, i.e. weighting scheme, normalisation scheme and inclusion/exclusion of variables had any effect on the output variance of the two states. In contrast, for Bayelsa state, the shock variable was the primary source of uncertainty in its composite score. Similarly, in Edo state, the primary source of uncertainty is from the shock 
variables. For both state, the individual influence between the input factors, do have an impact on the output variance as the total $S_{i}$ is above $100 \%$. The impact is mainly cause by the shock variable. This implies that the VFII is highly sensitive to shocks. The VFII is a food security indicator that incorporate vulnerability component. It is highly desirable that this index should be able to pick up the effect of the vulnerability component. As the index is highly sensitive to shocks, it proves that the index is reliable and meet the purpose for which it was design. Generally, input factors with a major contribution to variance of the VFII are: shock, child mortality stunting, hunger, wealth index, distance-to-road, distance- to-market and household literacy. Input with lesser contributions are: distance-to-water-source, income source, non-farm income, and crop yield.

The sum of the first order sensitivity index for the two states is greater than 1, implying that the VFII model is an additive model. A model is said to be additive when it is possible to decompose the variance of its input factor quantitatively. The entire input factor taken singly explain more than $100 \%$ of the output variance.

The total effect index represents the difference between the two states composite index score. It also measures how much an input factor interacts with other input factors. Our total effect sensitivity index $S_{T i}$ is less than $S_{i}$, this means that the input factors do interact with other input factors. However, the interaction between the input factors was low (-15.6\%) due to the influence of the shock variable. The difference between the two states composite scores is mostly attributed to the shock variable of each state with a high score of 0.90 and 0.10 respectively. The triggers had a lesser effect of the output variance of the two state. 
Table 9: Sobol sensitivity indices for composite scores of two states in South-Nigeria

\begin{tabular}{|c|c|c|c|}
\hline Input Factors & $\begin{array}{l}\text { First- order } \\
\left(S_{i} \text {-Bayelsa }\right)\end{array}$ & $\begin{array}{l}\text { First-order } \\
\left(S_{i} \text { Edo }\right)\end{array}$ & $\begin{array}{l}\text { Total effect }\left(S_{T i}\right. \\
\text { Edo-Bayelsa) }\end{array}$ \\
\hline Shock $_{b}$ & 1.06651 & 0 & 0.903442 \\
\hline Child Mortality $_{b}$ & 0.02805 & 0 & 0.019396 \\
\hline Stunting $_{b}$ & 0.004535 & 0 & 0.007513 \\
\hline Hunger $_{b}$ & -0.000784 & 0 & 0.00163 \\
\hline Wealth Index $x_{b}$ & 0.007421 & 0 & 0.00418 \\
\hline Dist - to $-\operatorname{Road}_{b}$ & 0.069542 & 0 & 0.052796 \\
\hline Dist - to - Water $_{b}$ & 0.001171 & 0 & 0.001117 \\
\hline 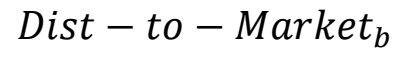 & 0.001643 & 0 & -0.00266 \\
\hline Income Source $_{b}$ & 0.000129 & 0 & 0.00042 \\
\hline Non farm Income $_{b}$ & 0.004479 & 0 & 0.002208 \\
\hline Crop Yield $_{b}$ & -0.00108 & 0 & -0.00109 \\
\hline Household Literacy $_{b}$ & -0.0253 & 0 & -0.0222 \\
\hline Shock $_{e}$ & 0 & 0.857508 & 0.107939 \\
\hline Child Mortality $_{e}$ & 0 & 0.033099 & 0.000859 \\
\hline Stunting $_{e}$ & 0 & 0.049124 & -0.000146 \\
\hline Hunger $_{e}$ & 0 & 0.038877 & -0.00287 \\
\hline Wealth Index $x_{e}$ & 0 & 0.078605 & 0.011006 \\
\hline Dist - to - Road $_{e}$ & 0 & 0.037927 & 0.005205 \\
\hline Dist - to - Water $_{e}$ & 0 & -0.00209 & 0.005037 \\
\hline Dist - to - Market $_{e}$ & 0 & 0.020292 & -0.00434 \\
\hline Income Source $_{e}$ & 0 & 0.005667 & 0.00061 \\
\hline Non farm Income $_{e}$ & 0 & -0.00402 & -0.000326 \\
\hline Crop Yield & 0 & -0.000695 & 0.000996 \\
\hline Household Literacye & 0 & 0.039294 & -0.0247 \\
\hline Weighting & 0 & 0 & $-5.55 \mathrm{E}-17$ \\
\hline Normalization & 0 & 0 & $-5.55 \mathrm{E}-17$ \\
\hline Inclusion/Exclusion & 0 & 0 & $-5.55 \mathrm{E}-17$ \\
\hline Sum & 1.156316 & 1.153588 & 1.066022 \\
\hline
\end{tabular}

Source: Data Analysis

\subsection{Conclusion}

This paper investigated the robustness of the Vulnerability to Food Insecurity Index. We carried out a robust check using sensitivity and uncertainty analysis on the following assumptions used to design the index:
a) alternative data type (missing data or complete data)
b) alternative weighting scheme (equal or unequal weight)
c) alternative normalization scheme (min-max or z-score method)
d) excluding or including variables. 
Using these assumptions, we collectively investigate the performance and the sources of uncertainty to the VFII, focusing on the following questions:

a) How does the output of the VFII rank compare to different assumptions?

b) What is the major source of uncertainty in the VFII ranking?

c) What are the most influential input factors that cause this uncertainty in VFII ranking?

The result of the analysis showed that: VFII result is stable to changes in variables and normalisation method when equal weight is applied. Using the min-max normalisation method produces highly robust estimate compare to using the $\mathrm{z}$-score method. The major source of input that introduces uncertainty to the VFII output was shock variable. Implying that the VFII is highly sensitive to shock, therefore better capturing the vulnerability component of food security. We conclude that the index is fit for purpose and will perform better than other indicators of food security in terms of vulnerability. 


\section{Appendix}

Appendix I: VFII score for each state using unequal weighting

\begin{tabular}{lllll}
\hline States & $\begin{array}{l}\text { VFII_Missing- } \\
\text { min-max }\end{array}$ & $\begin{array}{l}\text { VFII_Missing- } \\
\text { z-score }\end{array}$ & $\begin{array}{l}\text { VFII_Complete- } \\
\text { min-max }\end{array}$ & $\begin{array}{l}\text { VFII_Complete- } \\
\text { z-score }\end{array}$ \\
\hline Akwa & 0.677 & -0.047 & -0.130 & -0.456 \\
Ibom & & & & \\
Bayelsa & 0.689 & 0.309 & 0.033 & 0.834 \\
Cross & 0.574 & -0.360 & -0.051 & 0.668 \\
River & & & & \\
Delta & 0.731 & 0.162 & -0.166 & 0.069 \\
Edo & 0.666 & 0.072 & -0.036 & 0.418 \\
Rivers & 0.739 & 0.012 & -0.225 & -0.610 \\
\hline
\end{tabular}

Appendix II: VFII score for each state using equal weighting

\begin{tabular}{lllll}
\hline State & $\begin{array}{l}\text { VFII_missing- } \\
\text { min-max }\end{array}$ & $\begin{array}{l}\text { VFII_missing-z- } \\
\text { score }\end{array}$ & $\begin{array}{l}\text { VFII_complete- } \\
\text { min-max }\end{array}$ & $\begin{array}{l}\text { VFII_complete- } \\
\text { Z-score }\end{array}$ \\
\hline Bayelsa & -0.096 & -0.153 & -0.093 & -0.118 \\
Akwa & -0.092 & -0.103 & -0.093 & -0.075 \\
Ibom & & & & \\
Rivers & -0.092 & -0.021 & -0.091 & -0.037 \\
Delta & -0.072 & 0.007 & -0.082 & 0.007 \\
Cross & -0.072 & 0.041 & -0.065 & 0.077 \\
River & & & & \\
Edo & -0.047 & 0.168 & -0.041 & 0.153 \\
\hline
\end{tabular}

Appendix III: VFII score for excluding or including a variable

\begin{tabular}{llll}
\hline State & $\begin{array}{l}\text { Excluding } \\
\text { child } \\
\text { mortality }\end{array}$ & $\begin{array}{l}\text { Excluding child mortality } \\
\text { and }\end{array}$ & $\begin{array}{l}\text { Including child mortality } \\
\text { source }\end{array}$ \\
& -0.121 & -0.110 & -0.082 \\
distance-to-water- excluding distance to \\
Akwa Ibom & -0.120 & -0.109 & -0.080 \\
Rivers & -0.113 & -0.098 & -0.078 \\
Bayelsa & -0.107 & -0.096 & -0.071 \\
Delta & -0.088 & -0.077 & -0.054 \\
Cross River & -0.069 & -0.056 & -0.028 \\
Edo & & & \\
\hline
\end{tabular}

Appendix IV: Equal-weight used in designing VFII

\begin{tabular}{|c|c|c|c|c|c|c|}
\hline $\begin{array}{l}\text { VFII } \\
\text { component }\end{array}$ & Indicators & $\begin{array}{l}\text { Individual } \\
\text { weight }\end{array}$ & $\begin{array}{l}\text { Excluding } \\
\text { child } \\
\text { mortality }\end{array}$ & $\begin{array}{l}\text { Excluding } \\
\text { distance- } \\
\text { to-water }\end{array}$ & $\begin{array}{l}\text { Excluding } \\
\text { child } \\
\text { mortality }\end{array}$ & $\begin{array}{l}\text { Overall } \\
\text { weight }\end{array}$ \\
\hline
\end{tabular}




\begin{tabular}{|c|c|c|c|c|c|c|}
\hline & & & & source & $\begin{array}{l}\text { and } \\
\text { distance to } \\
\text { water } \\
\text { source }\end{array}$ & \\
\hline \multirow[t]{3}{*}{ Exposure } & Shocks & 0.33 & 0.33 & 0.33 & 0.33 & \multirow[t]{2}{*}{0.33} \\
\hline & Stunting & 0.11 & 0.165 & 0.11 & 0.165 & \\
\hline & $\begin{array}{l}\text { Child } \\
\text { mortality }\end{array}$ & 0.11 & - & 0.11 & - & \multirow[t]{2}{*}{0.33} \\
\hline \multirow{3}{*}{ Sensitivity } & Hunger & 0.11 & 0.165 & 0.11 & 0.165 & \\
\hline & $\begin{array}{l}\text { Wealth } \\
\text { Index }\end{array}$ & 0.04125 & 0.0412 & 0.0471 & 0.0471 & \multirow[t]{8}{*}{0.33} \\
\hline & $\begin{array}{l}\text { Road } \\
\text { distance }\end{array}$ & 0.0412 & 0.0412 & 0.0471 & 0.0471 & \\
\hline \multirow{6}{*}{$\begin{array}{l}\text { Adaptive } \\
\text { Capacity }\end{array}$} & Market & 0.0412 & 0.0412 & 0.0471 & 0.0471 & \\
\hline & $\begin{array}{l}\text { Water } \\
\text { source }\end{array}$ & 0.0412 & 0.0412 & - & - & \\
\hline & $\begin{array}{l}\text { Income } \\
\text { savings }\end{array}$ & 0.0412 & 0.0412 & 0.0471 & 0.0471 & \\
\hline & $\begin{array}{l}\text { Revenue } \\
\text { non-farm }\end{array}$ & 0.0412 & 0.0412 & 0.0471 & 0.0471 & \\
\hline & $\begin{array}{l}\text { Crop } \\
\text { Harvested }\end{array}$ & 0.0412 & 0.0412 & 0.0471 & 0.0471 & \\
\hline & Literacy & 0.0412 & 0.0412 & 0.0471 & 0.0471 & \\
\hline
\end{tabular}


Appendix V: Unequal weight used in designing VFII

\begin{tabular}{|c|c|c|c|}
\hline $\begin{array}{l}\text { VFII } \\
\text { component }\end{array}$ & Indicators & $\begin{array}{l}\text { Individual } \\
\text { weight }\end{array}$ & $\begin{array}{l}\text { Overall } \\
\text { weight }\end{array}$ \\
\hline Exposure & Shocks & 0.0871 & 0.0871 \\
\hline & Stunting & -0.0058 & \\
\hline Sensitivity & $\begin{array}{l}\text { Child } \\
\text { mortality }\end{array}$ & -0.2628 & -0.5645 \\
\hline \multirow{12}{*}{$\begin{array}{l}\text { Adaptive } \\
\text { Capacity }\end{array}$} & Hunger & -0.2959 & \multirow{12}{*}{1.1322} \\
\hline & Wealth & 0.5363 & \\
\hline & Index & & \\
\hline & $\begin{array}{l}\text { Road } \\
\text { distance }\end{array}$ & 0.0907 & \\
\hline & Market & 0.0607 & \\
\hline & Water & -0.3767 & \\
\hline & source & & \\
\hline & $\begin{array}{l}\text { Income } \\
\text { savings }\end{array}$ & 0.4437 & \\
\hline & $\begin{array}{l}\text { Revenue } \\
\text { non-farm }\end{array}$ & -0.0593 & \\
\hline & Crop & -0.0035 & \\
\hline & Harvested & & \\
\hline & Literacy & 0.4403 & \\
\hline
\end{tabular}


Appendix VI: Distributions $(\mu, \sigma)$ for inputs and triggers for inclusion-exclusion, missing data, weighting and normalisation method

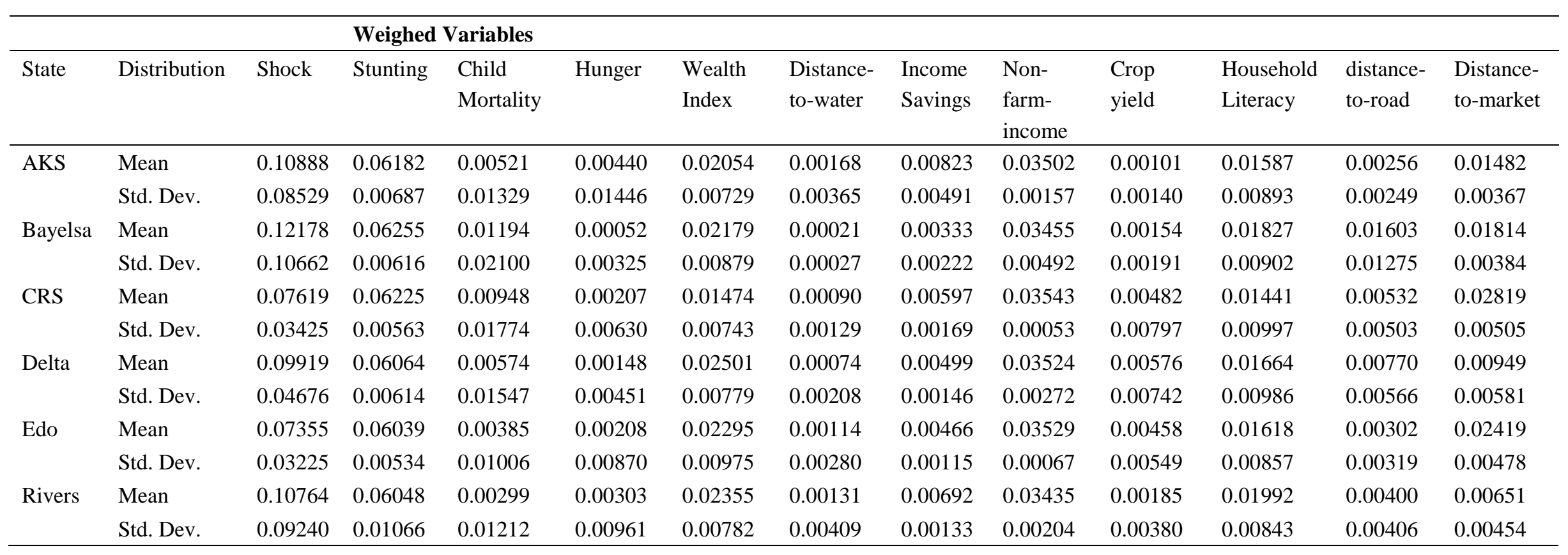




\section{Reference}

Abson, D. J., Dougill, A. J. \& Stringer, L. C. (2012). Using principal component analysis for information-rich socio-ecological vulnerability mapping in Southern Africa. Applied Geography, 35, 515-524.

Adepoju, A. O., Yusuf, S. A., Omonona, B. T. \& Okunmadewa, F. Y. (2011). Vulnerability profile of rural households in South West Nigeria. Journal of Agricultural Science, 3, 128-139.

Adger, W. N. (2006). Vulnerability. Global Environmental Change, 16, 268-281.

Alkire, S. \& Santos, M. E. (2014). Measuring acute poverty in the developing world: Robustness and scope of the multidimensional poverty index. World Development, 59, 251-274.

Antwi-Agyei, P., Fraser, E. D., Dougill, A. J., Stringer, L. C. \& Simelton, E. (2012). Mapping the vulnerability of crop production to drought in Ghana using rainfall, yield and socioeconomic data. Applied Geography, 32, 324-334.

Barrett, C. B. (2010). Measuring food insecurity. Science, 327, 825-828.

Bashir, M. K. \& Schilizzi, S. (2012). Measuring food security: Definitional sensitivity and implications. 56th Australian Agricultural \& Resource Economics Society annual conference. Western Australia.

Berkes, F. \& Folke, C. (1998). Linking social and ecological systems for resilience and sustainability. In: Berkes, F. \& Folke, C. (eds.) Linking social and ecological systems. Cambridge: Cambridge University Press.

Bickel, G., Nord, M., Price, C., Hamilton, W. \& Cook, J. (2000). Guide to measuring household food security. US Department of Agriculture, Food and Nutrition Service, Alexandria VA, 1-82.

Brooks, N., Adger, W. N. \& Kelly, P. M. (2005). The determinants of vulnerability and adaptive capacity at the national level and the implications for adaptation. Global environmental change, 15, 151-163.

Capaldo, J., Karfakis, P., Knowles, M. \& Smulders, M. (2010). A model of vulnerability to food insecurity. ESA working paper (No. 10-03), FAO: Rome.

Cardona, O. D., van Aalst, M. K., Birkmamm, J., Fordham, M., McGregor, G., Perez, R., Pulwarty, R. S., Schipper, E. L. F. \& Sinh, B. T. (2012). Determinants of risk: exposure and vulnerability. In: Field, C. B., Barros, V., Stocker, T. F., Qin, D., Dokken, D. J., Ebi, K. L., Mastrandread, M. D., Mach, K. J., Plattner, G. K., Allen, S. K., Tignor, M. \& Midgley, P. M. (eds.) Managing the risks of extreme events and diasters to advance climate change adaptation. Cambridge, UK, and New York, USA: A special Report of Working Groups I and II of the Intergovernmental Panel on Climate Change (IPPC).

Chaudhuri, S., Jalan, J. \& Suryahadi, A. (2002). Assessing households vulnerability to poverty from cross-sectional data: A methodology and estimates from Indonesia. New York: Columbia University.

Christiaensen, L. J. \& Boisvert, R. N. (2000). On measuring household food vulnerability: Case evidence from Northern Mali. Ithaca, NY: Department of Agricultural, Resource, and Managerial Economics, Cornell University.

Corral, P., Molini, V. \& Oseni, G. (2015). No condition is permanent: Middle class in Nigeria in the last decade. Policy research working paper 7214 . World Bank Group.

Dary, O. \& Imhoff-Kunsch, B. (2010). Guide to estimating per capita consumption of staple foods using Household Income and Expenditure Survey (HIES) data. ECSA/A2Z Monitoring and Evaluation Workshop. Uganda.

de Sherbinin, A. (2014). Spatial climate change vulnerability assessments: A review of data, methods, and issues. USA: United States Agency for International Development.

de Sherbinin, A., Chai-Onn, T., Giannini, A., Jaiteh, M., Levy, M., Mara, V., Pistoles, L. \& Trzaska, S. (2014). Mali climate vulnerability mapping. USA: United State Agency for International Development.

Deitchler, M., Ballard, T., Swindale, A. \& Coates, J. (2011). Introducing a simple measure of household hunger for cross-cultural use. Food and Nutrition Technical Assistance 2: Technical Note 12. Washington DC: USAID.

Dotter, C. \& Klasen, S. (2014). The Multidimensional Poverty Index: Achievements, Conceptual, and Empirical Issues. Occassional Paper. New York: UNDP Human Development Report Office.

Elbers, C. \& Gunning, J. W. (2003). Vulnerability in a Stochastic Dynamic Model. Ttinergen Institute Discusion Paper $T 1$ 2003-07/2. Amsterdam: Tinbergen Institute. 
Engle, N. L. (2011). Adaptive capacity and its assessment. Global Environmental Change, 21, 647656.

Esty, D. C., Levy, M., Srebitnjak, T., De Sherbinin, A., Kim, C. H. \& Anderson, B. (2006). Pilot 2006 Environmental Performance Index. New Haven: Yale Center for Environmental Law and Policy.

FAO (1968). Food composition table for use in Africa. In: Leung, W.-T. W., Busson, F. \& Jardin, C. (eds.). Maryland, USA: US Department of Health, Education and Welfare.

FAO (1996). World food summit-Rome declaration on world food security and WFS plan of action. Rome: WFS document. FAO.

FAO, INFOODS, WAHO \& BIODIVERSITY-INTERNATIONAL (2012). West African Food Composition Table. Rome: Food and Agriculture Organization of the United Nations.

FAO \& WHO (1996). Study on the impact of armed conflicts on the nutritional situation of children. Rome: Food and Agricultural Organization.

Fellmann, T. (Year). The assessment of climate change-related vulnerability in the agricultural sector: reviewing conceptual frameworks. In: Building resilience for adaptation to climate change in the agriculture sector. Proceedings of a Joint FAO/OECD Workshop, Rome, Italy, 23-24 April 2012., 2012. Food and Agriculture Organization of the United Nations (FAO), 37-61.

Freudenberg, M. (2003). Composite indicators of country performance: A critical assessment. Paris: OECD.

Fry, K., Firestone, R. \& Chakraborty, N. M. (2014). Measuring equity with national representative wealth quintiles. Washington, DC: PSI.

Gbetibouo, G. A., Ringler, C. \& Hassan, R. (2010). Vulnerability of the South African farming sector to climate change and variability: An indicator approach. Natural Resources Forum, 34, 175187.

Günther, I. \& Harttgen, K. (2009). Estimating households vulnerability to idiosyncratic and covariate shocks: A novel method applied in Madagascar. World Development, 37, 1222-1234.

Hahn, M. B., Riederer, A. M. \& Foster, S. O. (2009a). The Livelihood Vulnerability Index: A pragmatic approach to assessing risks from climate variability and change-A case study in Mozambique. Global Environmental Change, 19, 74-88.

Hahn, M. B., Riederer, A. M. \& Foster, S. O. (2009b). The Livelihood Vulnerability Index: A pragmatic approach to assessing risks from climate variability and change-A case study in Mozambique. Global Environmental Change, 19, 74-88.

Hinkel, J. (2011). "Indicators of vulnerability and adaptive capacity": Towards a clarification of the science-policy interface. Global Environmental Change, 21, 198-208.

Hoddinott, J. \& Quisumbing, A. (2003). Data sources for microeconometric risk and vulnerability assessments. Social Protection Discussion Paper Series NO. 0323. Washington D.C: World Bank.

Hoddinott, J. \& Quisumbing, A. (2008). Methods for microeconometric risk and vulnerability assessments. Washington D.C: International Food Policy Research Institute.

Homma, T. \& Saltelli, A. (1996). Importance measures in global sensitivity analysis of nonlinear models. Reliability Engineering \& System Safety, 52, 1-17.

Hoogeveen, J., Tesliuc, E., Vakis, R. \& Dercon, S. (2004). A guide to the analysis of risk, vulnerability and vulnerable groups. World Bank. Washington, DC. Available on line at http://siteresources. worldbank. org/INTSRM/Publications/20316319/RVA. pdf. Processed.

IPPC (2001). Climate change 2001: Impacts, Adaptation and Vulnerability. Contribution of Working Group II to the Third Assessment Report of the Intergovernmental Panel on Climate Change. In: McCarthy, J. J., Canziani, O. F., Leary, N. A., Dokken, D. J. \& White, K. S. (eds.). Cambridge, UK and New York, USA: Cambridge University Press.

IPPC (2007). Climate change 2007: Impacts, Adaptation and Vulnerability. Contribution of Working Group II to the Third Assessment Report of the Intergovernmental Panel on Climate Change. In: Parry, M. L., Canziani, O. F., Palutikof, J. P., Van der Linder, P. J. \& Hanson, C. E. (eds.). Cambridge, UK: Cambridge University Press.

Jones, A. D., Ngure, F. M., Pelto, G. \& Young, S. L. (2013a). What Are We Assessing When We Measure Food Security? A Compendium and Review of Current Metrics. Advances in Nutrition, 4, 481-505.

Jones, A. D., Ngure, F. M., Pelto, G. \& Young, S. L. (2013b). What Are We Assessing When We Measure Food Security? A Compendium and Review of Current Metrics. Advances in Nutrition, 4, 481-505. 
Karfakis, P., Knowles, M., Smulders, M. \& Capaldo, J. (2011). Effect of global warming on vulnerability in rural Nicaragua. ESA working paper No. 11-18. Rome: FAO.

Klennert, K. (ed.) (2005). Achieving food and nutrition security: Actions to meet the global challenge - A training course reader. Germany: Internationale Weiterbildung und Entwicklung gGmbH.

Krishnamurthy, P., Lewis, K. \& Choularton, R. (2014). A methodological framework for rapidly assessing the impacts of climate risk on national-level food security through a vulnerability index. Global Environmental Change, 25, 121-132.

Lovendal, C. R. \& Knowles, M. (2005). Tommorow's hunger: A framework for analyzing vulnerability to food insecurity. Rome: FAO.

LSHTM (2009). The use of epidemiological tools in conflict-affected populations: open-access educational resources for policy-makers. Calculation of z-scores. London: London School of Hygiene and Tropical Medicine.

Lucas, P. \& Hilderink, H. (2005). Vulnerability Concept and its Application to Food Security. RIVM rapport 550015004.

Madu, I. A. (2012). Spatial vulnerability of rural households to climate change in Nigeria: Implication for internal security. Working Paper No. 2. Texas: Robert S. Strauss centre for international security and law.

Malcomb, D. W., Weaver, E. A. \& Krakowka, A. R. (2014). Vulnerability modeling for sub-Saharan Africa: An operationalized approach in Malawi. Applied Geography, 48, 17-30.

Maxwell, D. \& Caldwell, R. (2008). The coping strategies index: field methods manual. 2 ed. Atlanta, GA: CARE.

Maxwell, D., Coates, J. \& Vaitla, B. (2013). How do different indicators of houseshold food security compare? Empirical evidence from Tigray. Medford:USA: Feinstein International Center, Tufts University.

Maxwell, D., Vaitla, B. \& Coates, J. (2014). How do indicators of household food insecurity measure up? An empirical comparison from Ethiopia. Food policy, 47, 107-116.

McCarthy, J. J., Canziani, O. F., Leary, N. A., Dokken, D. J. \& White, K. S. (eds.) (2001). Impacts, Adaptation and Vulnerability. Cambridge: Cambridge University Press.

Moss, R. H., Brenkert, A. L. \& Malone, E. L. (2001). Vulnerability to climate change: A quantitative approach. USA: United State Department of Energy.

NBS (2015). Basic Information Document: Nigeria General Household Survey - Panel 2010/2011. Nigeria: National Bureau of Statistics.

NBS \& LSMS (2015). Basic Information Document: Nigeria General Household Survey - Panel 2012/13. Nigeria: National Bureau of Statistics.

O'Brien, K., Eriksen, S., Nygaard, L. P. \& Schjolden, A. (2007). Why different interpretations of vulnerability matter in climate change discourses. Climate policy, 7, 73-88.

OECD (2008). Handbook on Constructing Composite Indicators: Methodology and User Guide. Italy: Joint Research Center, European commission.

Polsky, C., Neff, R. \& Yarnal, B. (2007). Building comparable global change vulnerability assessments: The vulnerability scoping diagram. Global Environmental Change, 17, 472-485.

Ruststein, S. O. \& Johnson, K. (2004). The DHS Wealth Index. Calverton, Maryland: ORC macro.

Saisana, M., Saltelli, A. \& Tarantola, S. (2005). Uncertainty and sensitivity analysis techniques as tools for the quality assessment of composite indicators. Journal of the Royal Statistical Society: Series A (Statistics in Society), 168, 307-323.

Saltelli, A. (2017). Sensitivity Analysis. Bergen: Centre for the study of Sciences and HumanitiesUniversity of Bergen.

Saltelli, A., Ratto, M., Andres, T., Campolongo, F., Cariboni, J., Gatelli, D., Saisana, M. \& Tarantola, S. (2008). Global sensitivity analysis: the primer. England: John Wiley \& Sons.

Saltelli, A., Tarantola, S., Campolongo, F. \& Ratto, M. (2004). Sensitivity analysis in practice: A guide to assessing scientific models. England: John Wiley \& Sons.

Scaramozzino, P. (2006). Measuring vulnerability to food security. Rome: ESA working paper (No. 06-12).

Singh, C. (2014). Understanding water scarcity and climate variability: an exploration of farmer vulnerability and response strategies in northwest India. Unpublished doctoral dissertation, University of Reading.

Smith, L. C. \& Subandoro, A. (2007). Measuring Food Security using household expenditure survey. Washington D.C: International Food Policy Research Institute. 
Sobol', I. (1996). On freezing of unessential variables. Moscow University Mathematics Bulletin, 51, 60-62.

Sobol', I. y. M. (1967). On the distribution of points in a cube and the approximate evaluation of integrals. USSR Computational Mathematics and Mathematical Physics, 7, 784-802.

Tarantola, S., Gatelli, D., Kucherenko, S. \& Mauntz, W. (2007). Estimating the approximation error when fixing unessential factors in global sensitivity analysis. Reliability Engineering \& System Safety, 92, 957-960.

UNDP (2007). Human Development Report 2007/2008: Fighting climate change: Human Solidarity in a divided world. New York, USA: United Nations Development Programme.

Vaitla, B., Coates, J., Glaeser, L., Hillbruner, C., Biswal, P. \& Maxwell, D. (2017). The measurement of household food security: Correlation and latent variable analysis of alternative indicators in a large multi-country dataset. Food Policy, 68, 193-205.

Villagrán de León, J. C. (2006). Vulnerability. A Conceptual and Methodological Review.

Webb, P. \& Bhatia, R. (2005). Manual: Measuring and Interpreting Malnutrition and Mortality. Nutr Serv WFP Rome.

WHO (2011). WHO child growth standards: WHO Anthro (version 3.2.2) and macros. Rome: World Health Organization.

Woller, G., Wolfe, J., Brand, M., Parrot, L., Fowler, B., Thompson, J., Dempsey, J., Berkowitz, L. \& van Haeften, B. (2013). Livelihood and food security conceptual framework. Livelihood and Food Security Technical Assistance. Washington, DC: FHI 360.

World-Bank \& NBS (2014). Nigeria General Household Survey -Panel 2012/2013. In: World-Bank \& National-Bureau-of-Statistics (eds.) Wave 1 ed. Nigeria.

World-Bank \& NBS (2015). Nigeria General Household Survey -Panel 2010/2011. In: World-Bank \& National-Bureau-of-Statistics (eds.) Wave 2 ed. Nigeria.

Young, H. \& Jaspars, S. (2006). The meaning and measurement of acute malnutrition in emergencies: A primer for decision-makers. London, UK: Overseas development institute (ODI). Humanitarian practice network (HPN). 